\title{
A wide field-of-view imaging DOAS instrument for two-dimensional trace gas mapping from aircraft
}

\author{
A. Schönhardt ${ }^{1}$, P. Altube ${ }^{1,2}$, K. Gerilowski ${ }^{1}$, S. Krautwurst ${ }^{1}$, J. Hartmann ${ }^{3}$, A. C. Meier ${ }^{1}$, A. Richter ${ }^{1}$, and \\ J. P. Burrows ${ }^{1}$ \\ ${ }^{1}$ Institute of Environmental Physics, University of Bremen, Germany \\ ${ }^{2}$ Dept. of Astronomy and Meteorology, University of Barcelona, Spain \\ ${ }^{3}$ Alfred-Wegener-Institute (AWI) Bremerhaven, Germany \\ Correspondence to: A. Schönhardt (schoenhardt@iup.physik.uni-bremen.de)
}

Received: 22 December 2013 - Published in Atmos. Meas. Tech. Discuss.: 8 April 2014

Revised: 31 October 2015 - Accepted: 8 November 2015 - Published: 9 December 2015

\begin{abstract}
The Airborne imaging differential optical absorption spectroscopy (DOAS) instrument for Measurements of Atmospheric Pollution (AirMAP) has been developed for the purpose of trace gas measurements and pollution mapping. The instrument has been characterized and successfully operated from aircraft. Nitrogen dioxide $\left(\mathrm{NO}_{2}\right)$ columns were retrieved from the AirMAP observations. A major benefit of the push-broom imaging instrument is the spatially continuous, gap-free measurement sequence independent of flight altitude, a valuable characteristic for mapping purposes. This is made possible by the use of a charge coupled device (CCD) frame-transfer detector. A broad field of view across track of around $48^{\circ}$ is achieved with wide-angle entrance optics. This leads to a swath width of about the same size as the flight altitude. The use of fibre coupled light intake optics with sorted light fibres allows flexible instrument positioning within the aircraft and retains the very good imaging capabilities. The measurements yield ground spatial resolutions below $100 \mathrm{~m}$ depending on flight altitude. The number of viewing directions is chosen from a maximum of 35 individual viewing directions (lines of sight, LOS) represented by 35 individual fibres. The selection is adapted to each situation by averaging according to signal-to-noise or spatial resolution requirements. Observations at $30 \mathrm{~m}$ spatial resolution are obtained when flying at $1000 \mathrm{~m}$ altitude and making use of all 35 viewing directions. This makes the instrument a suitable tool for mapping trace gas point sources and small-scale variability. The position and aircraft attitude are taken into account for accurate spatial mapping using the Attitude and Heading Reference System of the aircraft. A
\end{abstract}

first demonstration mission using AirMAP was undertaken in June 2011. AirMAP was operated on the AWI Polar-5 aircraft in the framework of the AIRMETH-2011 campaign. During a flight above a medium-sized coal-fired power plant in north-west Germany, AirMAP clearly detected the emission plume downwind from the exhaust stack, with $\mathrm{NO}_{2}$ vertical columns around $2 \times 10^{16}$ molecules $\mathrm{cm}^{-2}$ in the plume centre. $\mathrm{NO}_{x}$ emissions estimated from the AirMAP observations are consistent with reports in the European Pollutant Release and Transfer Register. Strong spatial gradients and variability in $\mathrm{NO}_{2}$ amounts across and along flight direction are observed, and small-scale enhancements of $\mathrm{NO}_{2}$ above a motorway are detected.

\section{Introduction}

Nitrogen dioxide, $\mathrm{NO}_{2}$, is an important trace gas in the Earth's atmosphere. $\mathrm{NO}_{2}$ and nitrogen monoxide, $\mathrm{NO}$, are coupled together by the reaction of $\mathrm{NO}$ with ozone, $\mathrm{O}_{3}$, which produces $\mathrm{NO}_{2}$ and the photolysis of the latter which produces NO. These processes are in steady state in an unperturbed situation, i.e. as long as no local NO pollution sources are present. Research interest in the sum of these two nitrogen oxides $\mathrm{NO}_{x}=\left(\mathrm{NO}_{2}+\mathrm{NO}\right)$ in the troposphere results from its harmful effects on human health (Nitschke et al., 1999, and references therein) and ecosystems (e.g. Galloway et al., 1982; Paerl, 1985). $\mathrm{NO}_{2}$ itself is toxic, but it also participates in catalytic cycles producing tropospheric ozone, $\mathrm{O}_{3}$. Tropospheric $\mathrm{O}_{3}$ is both a trace gas that impacts on air quality 
and a greenhouse gas. The main sources of $\mathrm{NO}_{x}$, apart from natural processes such as lightning, natural biomass burning events and soil emissions, are anthropogenic activities such as fossil fuel combustion by power plants, industry and traffic. The spatial and temporal variability of $\mathrm{NO}_{2}$ may be large due to variable and small-scale sources, the high reactivity of $\mathrm{NO}_{x}$ and a short atmospheric $\mathrm{NO}_{2}$ lifetime.

Since the 1970s, atmospheric $\mathrm{NO}_{2}$ amounts have been measured spectroscopically from the ground (Brewer et al., 1973; Noxon, 1975). A powerful and well-established method for the detection of atmospheric trace gases is the differential optical absorption spectroscopy (DOAS) technique (Platt and Perner, 1980; Platt and Stutz, 2008). Using the passive remote sensing DOAS method, the vertical column integrated amount of a trace gas can be determined from different platforms. Our knowledge about global distributions and temporal variation of $\mathrm{NO}_{2}$ has been increased by satellite observations from space (e.g. Burrows et al., 1999b; Leue et al., 2001; Richter and Burrows, 2002; Beirle et al., 2003; Richter et al., 2005; Bucsela et al., 2006; Hilboll et al., 2013) which provide valuable long-term and global data sets. Up to the present, spatial variability or point source emissions at spatial scales much below the order of several tens of kilometres, however, are not individually resolved from space-based measurements.

The ground-based DOAS technique has been further developed into the widely used MAX-DOAS (multiple axis DOAS) method, utilizing measurements at multiple elevation angles (Hönninger et al., 2004; Wittrock et al., 2004). These measurements provide information on the vertical trace gas profile. In addition to stationary set-ups, DOAS and MAXDOAS instruments have been used from ships (e.g. Peters et al., 2012), driving cars (Ibrahim et al., 2010) and airborne platforms. For example, DOAS measurements from high-altitude balloons yield $\mathrm{NO}_{2}$ columns and vertical profiles in the stratosphere (Pfeilsticker and Platt, 1994), and observations from aircraft yield tropospheric $\mathrm{NO}_{2}$ amounts over emission point sources and polluted regions (Melamed et al., 2003; Wang et al., 2005), as well as from shipping emissions (Berg et al., 2012). Such airborne measurements are also valuable for satellite validation (Heue et al., 2005). Observing in flight direction, Merlaud et al. (2012) apply a DOAS instrument on an ultralight aircraft and achieve high sensitivity for boundary layer $\mathrm{NO}_{2}$. Utilizing regular flights of an airliner, the CARIBIC project comprises DOAS measurements of several trace gases (Dix et al., 2009; Heue et al., 2011). The combination of multiple elevation angles in flight direction has enabled tropospheric $\mathrm{NO}_{2}$ profile retrievals from aircraft (Bruns et al., 2004, 2006). As a further development, Baidar et al. (2013) use a scanning unit as well as motion compensation for accurate selection of the desired elevation angles, with which they retrieve vertical profiles of trace gases and aerosols.

The extension of a DOAS instrument with one viewing direction at a time to an imaging design allows simultaneous observation in multiple independent directions within a large field of view. Imaging DOAS measurements have been performed from the ground (Lohberger et al., 2004; Bobrowski et al., 2006) and are regularly performed by the space-borne OMI (Ozone Monitoring Instrument) sensor (Levelt et al., 2006).

Two instrument applications of imaging DOAS from aircraft have already been reported which are based on two considerably different instrumental systems. Heue et al. (2008) report on the first imaging DOAS measurements from aircraft observing large-scale $\mathrm{NO}_{2}$ emissions over the South African Highveld power plants. The instrument is based on a commercial grating spectrometer as in the present study. Popp et al. (2012) use the APEX hyperspectral imaging spectrometer for successful $\mathrm{NO}_{2}$ observations over a city. That instrument has been developed within a broad ESA programme since 1993 and built by an industrial consortium. First data became available in 2008 (Itten et al., 2008).

Recently, the new imaging instrument, HAIDI (Heidelberg Airborne Imaging DOAS Instrument), has been reported, which has been successfully applied to measurements of $\mathrm{NO}_{2}, \mathrm{SO}_{2}, \mathrm{BrO}$ and $\mathrm{OClO}$ from anthropogenic emissions, in Polar regions and within volcanic plumes (General et al., 2014, 2015). The HAIDI consists of three DOAS instruments which point in different directions and are used either in whisk-broom or push-broom mode (Schowengerdt, 2007). Observations yield spatial trace gas distributions at ground resolutions below $100 \mathrm{~m}$ depending on flight altitude, as well as information on the vertical distribution.

The present study introduces the push-broom Airborne imaging DOAS instrument for Measurements of Atmospheric Pollution (AirMAP), which is well suited for trace gas mapping of comparably small-scale emissions at fine spatial resolution. The full spatial coverage within the given swath is independent of flight altitude, aircraft speed and measurement sequence. The wide and continuous spatial coverage is supported by (a) a large field of view of $48^{\circ}$ across track and (b) a measurement sequence without temporal gaps between consecutive exposures. At the same time, a good imaging quality is achieved. In the following, the instrumental set-up and viewing geometry as well as the attitude correction for accurate geolocation are introduced. The instrument quality is demonstrated in terms of spatial and spectral resolution as well as the $\mathrm{NO}_{2}$ retrieval quality. Some observations of $\mathrm{NO}_{2}$ are discussed, and the emission flux for a medium-sized power plant is calculated as an application example.

\section{Aircraft, flight and target description}

The research flight on 4 June 2011 took place in the framework of AIRMETH-2011, a joint campaign between the AWI Bremerhaven, IUP Bremen and GFZ Potsdam. The AirMAP instrument flew as additional payload during the 
campaign on the Polar-5, the AWI DC-3 research aircraft. The research aircraft is equipped with an AIMMS-20 (Aircraft-Integrated Meteorological Measurement System), comprising an AHRS (Attitude and Heading Reference System) and a GPS (Global Positioning System). The main target of the research flight was the observation of pollution plumes from a coal mine with a coal-fired power plant close by, the RWE Power AG Kraftwerk Ibbenbüren, at coordinates $7.748^{\circ} \mathrm{E}$ and $52.289^{\circ} \mathrm{N}$. One research focus addressed the emissions of methane, $\mathrm{CH}_{4}$, from ventilation shafts (Krings et al., 2013), for which the flight patterns were primarily selected. The medium-sized power plant generates an average power of around $840 \mathrm{MW}$, it has a $275 \mathrm{~m}$ high exhaust stack and uses extensive flue gas cleaning facilities. This information is reported by RWE Generation SE at http://www.rwe.com/web/cms/de/1770936/ rwe-generation-se/standorte/deutschland/kw-ibbenbueren (visited 11 December 2013). Emissions of around $3060 \mathrm{t} \mathrm{a}^{-1}$ of nitrogen oxides $\left(\mathrm{NO}_{x}\right.$ in weights of $\left.\mathrm{NO}_{2}\right)$ are reported for the year 2011 following E-PRTR, the European Pollutant Release and Transfer Register, http://prtr.ec.europa.eu (visited 11 December 2013). Emissions are variable from year to year, with reported amounts between 1900 and $3300 \mathrm{t} \mathrm{a}^{-1}$ for 2007 to 2010 . The aircraft survey above the target area took place between 09:05 and 10:20 UTC at an average flight altitude of around $1100 \mathrm{~m}$. The $\mathrm{NO}_{2}$ column amount was observed during multiple overpasses over the power plant exhaust plume.

\section{Instrumental set-up}

A sketch of the AirMAP instrumental set-up is shown in Fig. 1. The instrument comprises an Acton 300i imaging spectrograph with a focal length of $300 \mathrm{~mm}$ and an $f$ number of $f / 3.9$. It is equipped with a 600 lines $/ \mathrm{mm}$ grating blazed at $500 \mathrm{~nm}$, enabling measurements of the incoming light in the visible wavelength range from 412 to $453 \mathrm{~nm}$. The temperature of the spectrometer is stabilized at $35^{\circ} \mathrm{C}$. While the same spectrometer was used as by Bruns (2004) and Heue et al. (2008), the other parts of the instrument and its operation have rather different characteristics.

Viewing in nadir geometry, a wide-angle camera objective with $8 \mathrm{~mm}$ focal length is used as entrance optics allowing for a large field of view of about $48^{\circ}$ across track. The observed ground scene is imaged onto the entrance of a light guide consisting of 38 sorted single glass fibres, which are vertically aligned in the same sequence at either end with a centre-to-centre separation of $220 \mu \mathrm{m}$. The dimension of the fibres without cladding is $193 \mu \mathrm{m}$. The distance from one fibre to the next determines the limit of the spatial resolution in across-flight direction in terms of viewing angle. The decoupling of the entrance optics from the instrument by the use of this sorted light guide allows both optical imaging and flexible positioning of the instrument within the aircraft. On

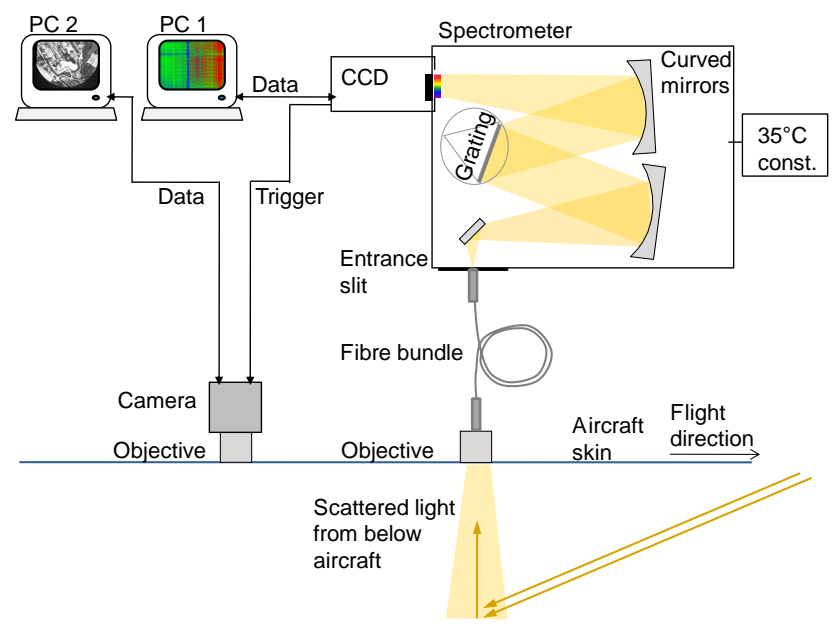

Figure 1. Sketch of the imaging DOAS instrument set-up with two nadir viewing wide-angle objectives, one objective directing the backscattered radiation via a sorted glass fibre bundle into an imaging spectrometer where the radiation is recorded by a frame-transfer $\mathrm{CCD}$, and one objective collecting the incoming radiation for direct scene photography and additional pointing information.

the spectrometer side, the light guide is attached to the entrance slit (approximately $100 \mu \mathrm{m}$ width) in the focal plane. Via the imaging spectrometer the spatial information of the radiance is retained, and the intensity spectrum is recorded by a 2-D CCD (charge coupled device) detector. The combination of the imaging spectrometer and the 2-D detector enables the push-broom imaging technique, where the field of view across track is observed simultaneously. In contrast, whisk-broom imagers scan over the swath measuring in different viewing directions in a rapid sequence (Schowengerdt, 2007).

A further feature of AirMAP is the specific choice of the CCD detector, which is a frame-transfer camera. The frametransfer technique allows gap-free measurements along flight direction. The detector comprises a two-fold chip area, an imaging area which is illuminated by the observed scene and a masked storage area. After an exposure, the charge on the $\mathrm{CCD}$ is shifted rapidly from the illuminated to the storage area. The illuminated area is ready for a new exposure while the former image is read out. The chip has a size of $512 \times 512$ pixels, a digitization rate of $5 \mathrm{MHz}$ and a vertical shift rate of $2 \mu \mathrm{s} /$ row. The frame-transfer set-up allows the idle time of the instrument to be reduced by a factor of around 70 in comparison to an equivalent detector without a storage area, as the shift time alone is $1 \mathrm{~ms}$ for the transfer of an entire image to the storage area, which is much faster than the readout time. The full frame read-out time of the second area here is typically slightly less than $0.1 \mathrm{~s}$. In addition, the image transfer to the storage area is much faster (by a factor of 500) than the exposure time of $0.5 \mathrm{~s}$, so the smear effect is negligible and no mechanical shutter is required for this 
short time. Effectively, no observational gaps occur between two subsequent measurements. During the test flights, once every 120 exposures (once per minute) a re-initialization of the detector was performed in order to prevent potential synchronization offsets with the GPS time. During the initialization, small observational gaps occur along track; however, this procedure is not generally necessary.

The following instrumental parts of AirMAP are similar to those described for the MAMAP instrument (Gerilowski et al., 2011). A second nadir viewing port is used for scene photography. The release of the employed $1 / 2^{\prime \prime} \mathrm{CCD}$ camera is triggered by the recordings of the spectrometer CCD. This way, alongside the trace gas measurements, corresponding photographic images for additional scene and position control are taken. The images are used for interpretation of the ground scene, e.g. to identify pollution sources. A Panel PC with SSD (solid state disk) memory is used for measurement control and data storage. The SSD provides fast reading and writing speed as well as comparably good vibration stability and, most importantly, safe operation also in higher flight altitudes at low pressure. A second compact PC is used for control of the image camera. For position and orientation monitoring, a Garmin $5 \mathrm{~Hz}$ GPS antenna as well as a small Microstrain 3DM-GX1 AHRS system are included in AirMAP.

\section{Viewing geometry}

\subsection{Field of view}

A sketch of the viewing geometry is shown in Fig. 2. AirMAP observes from an aircraft nadir port downwards, measuring the solar electromagnetic radiation that is backscattered by the ground or atmosphere to the entrance objective. Radiation from a field of view (FOV) of around $48^{\circ}$ across track is observed simultaneously. From the fibre bundle with an entire height of $8.5 \mathrm{~mm}$, the radiation from 35 of the 38 individual fibres is recorded by the CCD with a chip height of $8.2 \mathrm{~mm}$. Thus, a maximum of 35 individual viewing directions can be separated at a time. The instantaneous FOV (IFOV) along track is around $1.2^{\circ}$, while the effective FOV along track is given by the convolution of the IFOV with the travelled distance (i.e. the product of flight speed and exposure time). The along-track IFOV projected onto the ground is usually smaller than the travelled distance during the exposure time and is therefore neglected in the trace gas maps. The length of displayed ground pixels in flight direction is determined here by the travelled distance during one exposure, also taking into account the aircraft attitude at the start and end of an exposure.

Typical flight speed during the central flight pattern (i.e. the flight path above the power plant area) is around $60 \mathrm{~m} \mathrm{~s}^{-1}$. With an exposure time of $0.5 \mathrm{~s}$, a ground pixel size of $30 \mathrm{~m}$ along track is achieved.

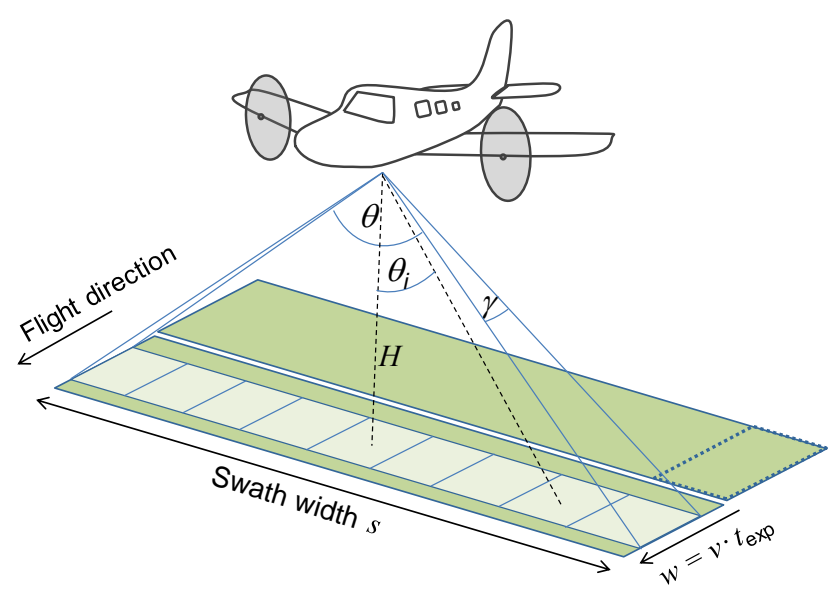

Figure 2. Sketch of the in-flight viewing geometry of the imaging DOAS instrument with flight altitude $H$, swath width $s$, single pixel length $w=v \cdot t_{\exp }$, flight speed $v$ and exposure time $t_{\exp }$ and the instantaneous FOV along track (defined by opening angle $\gamma$ ) and across track (opening angle $\theta$ ). The FOV across track is divided into individual viewing directions $\theta_{i}$.

The lines of sight, LOS, across track are spread between $\pm 24^{\circ}$ at level flight. With respect to flight direction, positive LOS values point to the right. At a typical flight altitude of around $1100 \mathrm{~m}$ a ground swath width of nearly $1000 \mathrm{~m}$ is covered. Averaging over neighbouring viewing directions and/or over time along track may be applied during postprocessing depending on the respective research focus, e.g. depending on the spatial extent of observed sources and required signal-to-noise ratio. All values reported in the present study are derived from the original $0.5 \mathrm{~s}$ exposures without temporal averaging. Specifications for ground resolution and spatial imaging quality follow below in Sect. 5.1.

\subsection{Aircraft angles and correction of geolocation}

Under flight conditions, the viewing geometry as described above is impacted by the aircraft attitude, i.e. the pitch, roll and yaw (heading) angles. For an accurately computed geolocation, required for source assignment and the determination of distances, it is essential to take into account the aircraft orientation and its altitude in addition to the latitude and longitude positions. Positioning information is either taken from the AirMAP GPS and AHRS, or it is received from the AIMMS-20 AHRS on board the research aircraft. The latter is used in the current study. By convention, the pitch angle is positive when the aircraft nose is pointing upwards, the roll angle is positive when the right wing is down and the yaw angle is counted positive from north $\left(0^{\circ}\right)$ in clockwise direction, i.e. towards the east.

The information of the aircraft positioning is read twice, viz. at the start and the end of each exposure. To map the trace gas amounts, the coordinates of the four corners of each ground pixel are computed - two corners for conditions at the 
exposure start, and two for the end conditions. Linear variation of all parameters during the fairly short exposure time of $0.5 \mathrm{~s}$ is assumed, so that the ground pixel is a tetragon. The across-track limits of an individual ground pixel are given by two individual LOS angles, $\theta_{i}$, with respect to the centre of the entire FOV. From the pitch $\left(\alpha_{\mathrm{p}}\right)$ and roll $\left(\alpha_{\mathrm{r}}\right)$ angles, the spatial displacements of the corner ground locations along $(L)$ and across $(d)$ flight direction can be calculated, whereby $H$ denotes the flight altitude above ground level (a.g.l.).

$$
\begin{aligned}
L & =H \cdot \tan \left(\alpha_{\mathrm{p}}\right) \\
d & =\frac{H}{\cos \left(\alpha_{\mathrm{p}}\right)} \cdot \tan \left(\theta_{i}-\alpha_{\mathrm{r}}\right)
\end{aligned}
$$

Starting from the aircraft location with latitude $\phi_{0}$ and longitude $\lambda_{0}$, a corner coordinate $(\phi, \lambda)$ deviates from the centre by $\phi^{\prime}$ and $\lambda^{\prime}$ and is calculated at a given time instance for each individual corner by using the above displacements, the aircraft yaw angle $\left(\alpha_{y}\right)$ and the Earth radius $R_{0}$ :

$$
\left(\begin{array}{l}
\lambda \\
\phi
\end{array}\right)=\left(\begin{array}{l}
\lambda_{0} \\
\phi_{0}
\end{array}\right)+\left(\begin{array}{c}
\lambda^{\prime} \\
\phi^{\prime}
\end{array}\right)
$$

with

$$
\left(\begin{array}{c}
\lambda^{\prime} \\
\phi^{\prime}
\end{array}\right)=\frac{180^{\circ}}{\pi R_{0}}\left(\begin{array}{ll}
\frac{\cos \alpha_{y}}{\cos \phi_{0}} & \frac{\sin \alpha_{y}}{\cos \phi_{0}} \\
-\sin \alpha_{y} & \cos \alpha_{y}
\end{array}\right)\left(\begin{array}{l}
d \\
L
\end{array}\right) .
$$

This results in

$$
\begin{aligned}
\lambda^{\prime} & =\frac{180^{\circ} \cdot H}{\pi R_{0} \cos \phi_{0}}\left(\cos \alpha_{y} \frac{\tan \left(\theta_{i}-\alpha_{\mathrm{r}}\right)}{\cos \alpha_{\mathrm{p}}}+\sin \alpha_{y} \tan \alpha_{\mathrm{p}}\right) \\
\phi^{\prime} & =\frac{180^{\circ} \cdot H}{\pi R_{0}}\left(-\sin \alpha_{y} \frac{\tan \left(\theta_{i}-\alpha_{\mathrm{r}}\right)}{\cos \alpha_{\mathrm{p}}}+\cos \alpha_{y} \tan \alpha_{\mathrm{p}}\right) .
\end{aligned}
$$

During most survey flights, where the pitch angle and altitude do not change much, the roll angle has the largest influence on the spatial displacement. Also during straight flight legs, the aircraft is often not exactly levelled. For the example flight discussed in Sect. 2, the average displacement magnitude over fairly straight tracks (with $\alpha_{\mathrm{r}} \leq 5^{\circ}$ ) lies around $60 \mathrm{~m}$, while for curved tracks (with $\alpha_{\mathrm{r}}>5^{\circ}$ ), the displacement mostly lies between 300 and $400 \mathrm{~m}$ with maxima up to between $700 \mathrm{~m}$ (central viewing direction) and $1200 \mathrm{~m}$ (sideways viewing direction). Application of the above correction is hence essential for accurate geolocation.

For part of the flight described in Sect. 2, Fig. 3 shows an image of the recorded radiation intensity mapped onto the ground (left) together with a Google Earth image (right). The image contains a piece of a motorway, which is visible in the measurements by the enhanced intensity. The intensity map is a composite of several passes over the motorway in different orientations, at different locations, and also during fairly curved paths. Nevertheless, the motorway, i.e. the enhanced intensity, shows a continuous course and is positioned at the correct location, demonstrating the good performance of the computed geolocation.

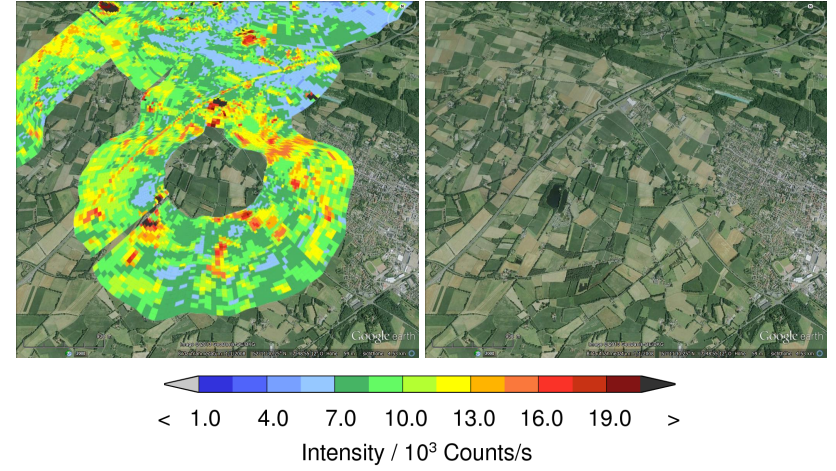

Figure 3. Demonstration of the good performance of the geolocation determined from the instrument field of view and correction by the aircraft angles during a curve. The recorded light intensity (left) shows high reflectivity of the motorway also seen in the Google Earth image (right, www.google.com/earth). The motorway is observed by a composite of three differently oriented overpasses and appears continuous and in the correct position.

\section{Instrument quality}

The performance of the imaging DOAS instrument has been tested in terms of its spatial, as well as its spectral characteristics. Spatial resolution and imaging qualities are important aspects for small-scale observations and subsequent source identification and attribution. In the spectral range, sufficient resolution for application of the DOAS technique and a wellshaped, stable spectral response function (SRF), commonly termed "slit function", are required. The retrieval quality of the $\mathrm{NO}_{2}$ absorption signal is discussed in Sect. 6.2.

\subsection{Spatial resolution and imaging quality}

Following from the field of view described in Sect. 4, a flight altitude of typically around $H=1100 \mathrm{~m}$ above ground level yields a swath width of $980 \mathrm{~m}$ and an individual pixel size of $28 \mathrm{~m}$ across track using full resolution. When combining spectra from adjacent fibres, e.g. to a number of nine LOS $(8 \times 4$ fibres and one LOS with three fibres at the upper CCD edge), the effective ground pixel size is increased to around $110 \mathrm{~m}$ while improving the SNR by about a factor of 2 . In order to further improve the SNR, subsequent detector readouts may be averaged, increasing the integration time, e.g. from 0.5 to $2 \mathrm{~s}$. This increases the ground pixel size to $120 \mathrm{~m}$ along track and the SNR again by a factor of 2. As the entire pixel-by-pixel read-out of each CCD exposure is stored, spatial and temporal averaging and choices of viewing directions may be performed during post-flight data evaluation, depending on the respective research question.

The instrument's optics have been carefully adjusted for the imaging of distant objects (practically close to infinity) before flight in the laboratory. An example image on the CCD chip is shown in Fig. 4. On the left, the scene photo- 


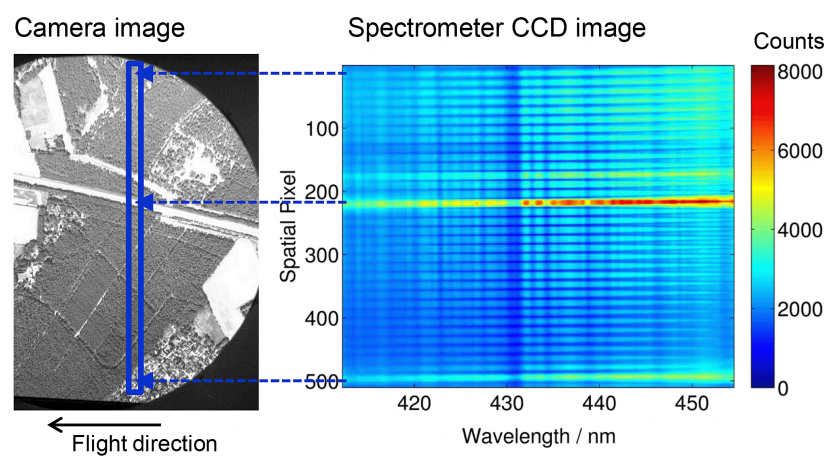

Figure 4. Example scene from a flight along a highly reflecting motorway in the centre of the field of view. Left: visual image of the observed scene, the spectrometer field of view marked by the blue box. Right: intensity recording on the 2-D CCD chip, with spectral information distributed along the horizontal axis and spatial information on the vertical axis. The horizontal stripes on the CCD image are caused by the 35 light fibres, the enhanced intensity from the bright motorway being visible only in one of the fibres.

graph in black and white is shown; the simultaneous CCD image of the DOAS measurement is shown on the right. In the CCD image, the horizontal axis contains the spectral information, while spatial information is distributed along the vertical axis. The blue box in the photograph marks the field of view for the DOAS observation. The CCD figure shows 35 illuminated stripes from the 35 glass fibres. The strongly reflecting motorway in the centre of the photograph causes high intensity only in one fibre, i.e. within one stripe on the CCD. Other features such as the smaller road above the motorway and the bright area towards the bottom of the picture can also be distinguished in the CCD image. The good imaging quality also allows the fine mapping of the motorway seen before in Fig. 3.

\subsection{Spectral resolution and spectral response function}

Due to image aberrations for off-axis object points, the SRF has a different shape and width for the different viewing angles. In addition, the image quality along the spatial axis is slightly degraded towards the detector edges. However, the individual spatial directions remain well separated. The narrowest SRF is that one of the central viewing direction with a FWHM (full width at half maximum) of $0.5 \mathrm{~nm}$, while the outermost viewing directions have an SRF with a FWHM of around $1.0 \mathrm{~nm}$. The experimental SRF measured at $435.8 \mathrm{~nm}$ with a $\mathrm{HgCd}$ calibration lamp is displayed in Fig. 5. From the centre to the outer directions, lighter colours are used. The viewing directions to the right are drawn as solid lines; directions to the left are drawn as dotted lines. With a sampling of $512 \mathrm{pix} / 41 \mathrm{~nm}=12.5 \mathrm{pix} / \mathrm{nm}$, i.e. between 6 and 12 pix/FWHM, the Nyquist sampling theorem is well fulfilled. The broadening of the point spread function towards the outer directions is clearly visible. The central directions

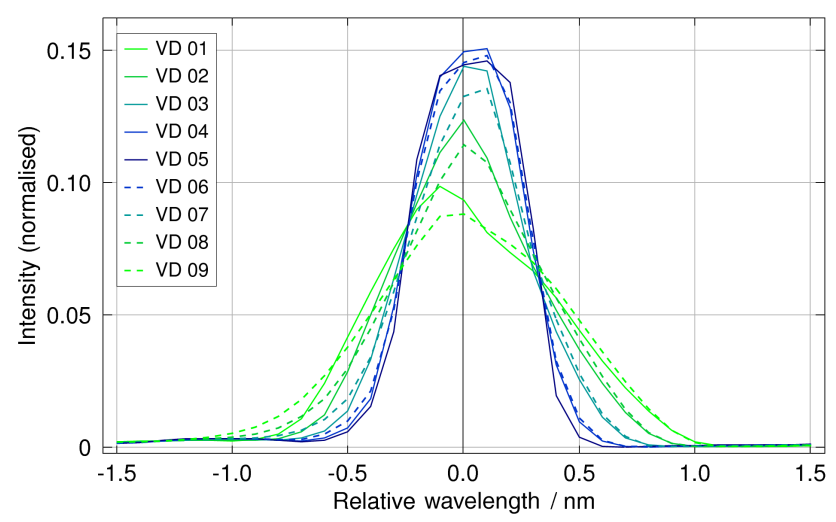

Figure 5. Experimental slit functions of the AirMAP instrument for campaign conditions in June 2011. The spectral resolution lies between 0.5 and $1.0 \mathrm{~nm}$ for the central and the outer viewing directions, respectively.

reveal good symmetry, while the two outermost viewing directions (VD 01 and 09) show some deviation in form of a dent to the right of the SRF centre. Most importantly, the SRF shape and width for each individual viewing direction are reasonably constant along the wavelength axis (not shown). Such a dependency may in general occur and would become more important for larger CCD chips. However, no variations in the SRF spectral shape were detected in laboratory tests with the AirMAP. This stability is required for accurate and consistent trace gas retrieval results.

\section{Observations of $\mathrm{NO}_{2}$}

The measurements of the AirMAP instrument have been used to retrieve trace gas absorption signals using the DOAS method. The current instrumental set-up allows observations within a spectral range of around $41 \mathrm{~nm}$. For the present study, the recorded spectral range was from 412 to $453 \mathrm{~nm}$. This spectral band covers strong spectral features of the $\mathrm{NO}_{2}$ absorption cross section.

\subsection{Retrieval settings}

For the retrieval of $\mathrm{NO}_{2}$ slant column densities, the spectral region from 425 to $450 \mathrm{~nm}$ is used as a fitting window. As a background reference, spectra that only slightly differ in time are used, averaged over a $1 \mathrm{~min}$ time period from above a rural region. Therefore, the retrieved $\mathrm{NO}_{2}$ amount is a differential slant column density (dSCD, hereafter SC) amount with respect to this background column. This approach effectively removes the absorption of any $\mathrm{NO}_{2}$ in the upper troposphere or stratosphere, where the $\mathrm{NO}_{2}$ is well mixed over horizontal scales of $50 \mathrm{~km}$ as a result of the high wind speed, mean free paths and related mixing. Using SCIAMACHY satellite data (Richter et al., 2005), also available at http: //www.iup.uni-bremen.de/doas/data_products.htm, the $\mathrm{NO}_{2}$ 


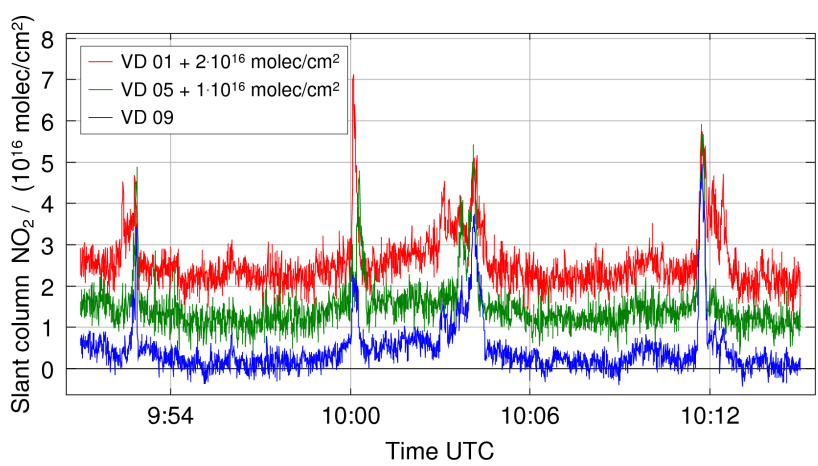

Figure 6. Excerpt of the $\mathrm{NO}_{2}$ time series measured at high temporal resolution ( $0.5 \mathrm{~s}$ exposure time) during the flight on 4 June 2011, here for three of the nine viewing directions, VD 01, VD 05 and VD 09, offset against one another for better visibility. Significant spatial variation of $\mathrm{NO}_{2}$ amounts is visible along the time axis (along track) as well as between the single viewing directions (across track).

product indicates that the stratospheric $\mathrm{NO}_{2}$ amount was about $4.0 \times 10^{15}$ molecules $\mathrm{cm}^{-2}$ for the time and location of the research flight. The small diurnal variation of this stratospheric $\mathrm{NO}_{2}$ column and the effect of changing the solar zenith angle (SZA) close to local noon are negligible. This is also because of the short time between the actual and the background measurement, which is $1 \mathrm{~h}$ at maximum for the measurements discussed in this study.

In addition to the $\mathrm{NO}_{2}$ absorption cross section $(293 \mathrm{~K}$, Burrows et al., 1998) the absorption signatures of $\mathrm{O}_{3}(241 \mathrm{~K}$, Burrows et al., 1999a), O 4 (296 K, Greenblatt et al., 1990) and $\mathrm{H}_{2} \mathrm{O}$ vapour (HITRAN 2004 data base, Rothman et al., 2005) are taken into account. A quadratic polynomial accounts for the broad-band spectral structures, and a constant intensity offset is fitted. In order to account for the in-filling of Fraunhofer lines in scattered light measurements, the Ring effect spectrum determined by radiative transfer calculations (Vountas et al., 2003) is also fitted as a pseudo-absorber. Prior to the actual retrieval procedure, all reference spectra are convolved with the instrument's SRF, individually for each viewing direction.

\section{2 $\mathrm{NO}_{2}$ slant columns and retrieval quality}

During the measurement flight, the retrieved $\mathrm{SC}$ of $\mathrm{NO}_{2}$ varies between values around 0 for areas which are similarly unpolluted as the rural reference region, and $5 \times 10^{16}$ molec $\mathrm{cm}^{-2}$ for locations most strongly affected by local $\mathrm{NO}_{x}$ emissions. Small negative $\mathrm{SC}$ values in some locations indicate cleaner conditions and thus lower $\mathrm{NO}_{2}$ amounts than in the reference region average. All results in this section refer to division of the field of view into nine viewing directions (referred to as LOS09 retrieval) at $0.5 \mathrm{~s}$ exposure time. A short part of the $\mathrm{NO}_{2}$ slant column time series is shown in Fig. 6, covering a 24 min period from 09:51

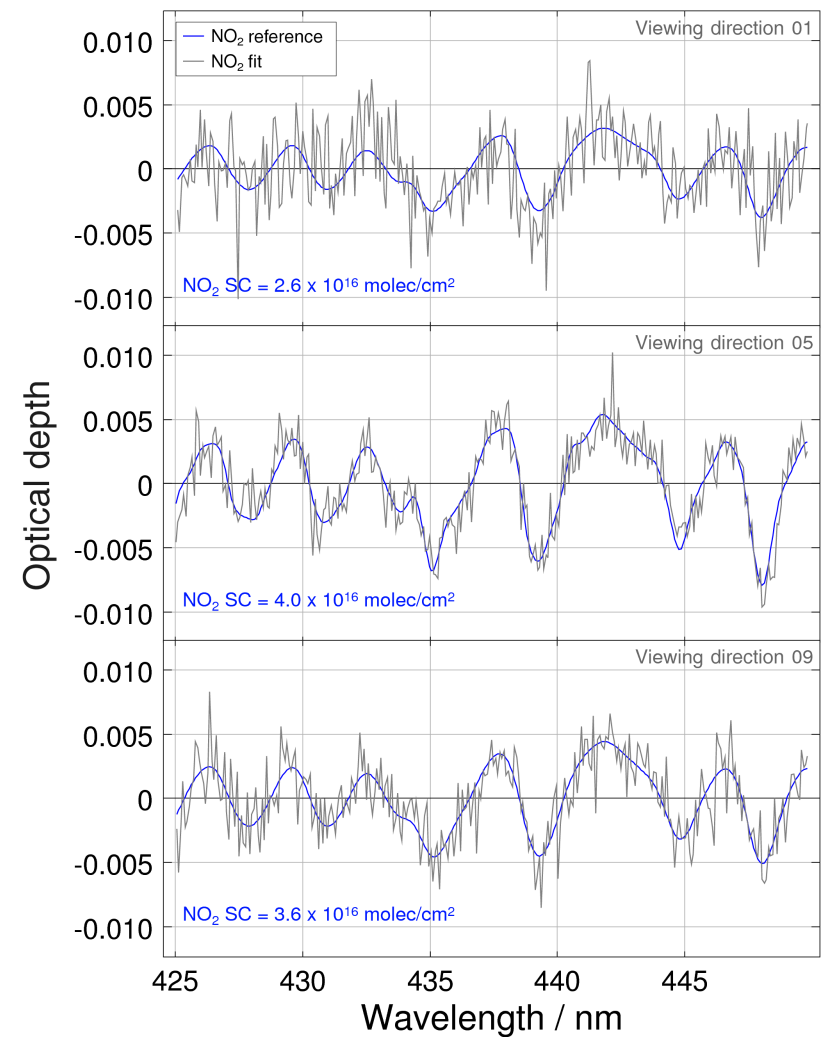

Figure 7. Example $\mathrm{NO}_{2}$ fit results for 4 June 2011, 10:11:47 UTC, for three of the nine different viewing directions, VD 01, VD 05 and VD 09. The respective $\mathrm{NO}_{2}$ slant columns are given in the figures.

to $10: 15 \mathrm{UTC}$ for three viewing directions, the furthest right (VD 01), centre (VD 05) and furthest left (VD 09) with respect to flight direction. Results of VD 01 and VD 05 are offset against VD 09 for better visibility by $2 \times 10^{16} \mathrm{molec} \mathrm{cm}^{-2}$ and $1 \times 10^{16}$ molec $\mathrm{cm}^{-2}$, respectively. With an exposure time of $0.5 \mathrm{~s}$ this high-resolution time series shows significant spatial variations along flight direction, i.e. along the time axis, as well as considerable spatial variation in acrossflight direction, visible through the differences between the three viewing directions. Some of the variation is due to noise, which is in the range of a few times $10^{15}$ molec $\mathrm{cm}^{-2}$ for the slant columns as discussed below. The observed variations along and across flight direction are clearly larger than the noise alone.

Example fit results for the measurement time 10:11:47 UTC are shown in Fig. 7 for the same selected viewing directions. For the given location, all three viewing directions show enhanced $\mathrm{NO}_{2}$ amounts with slant column densities of $\mathrm{SC}_{\mathrm{VD} 01}=2.6 \pm 0.2 \times 10^{16} \mathrm{molec} \mathrm{cm}^{-2}$, $\mathrm{SC}_{\mathrm{VD} 05}=4.0 \pm 0.1 \times 10^{16}$ molec cm $^{-2}$ and $\mathrm{SC}_{\mathrm{VD} 09}=$ $3.6 \pm 0.2 \times 10^{16} \mathrm{molec} \mathrm{cm}^{-2}$, respectively. Individual relative fitting errors range between 3 and $9 \%$ for the given examples. The root-mean-square (RMS) value of the residual optical depth gives a measure of the fit quality and of the 


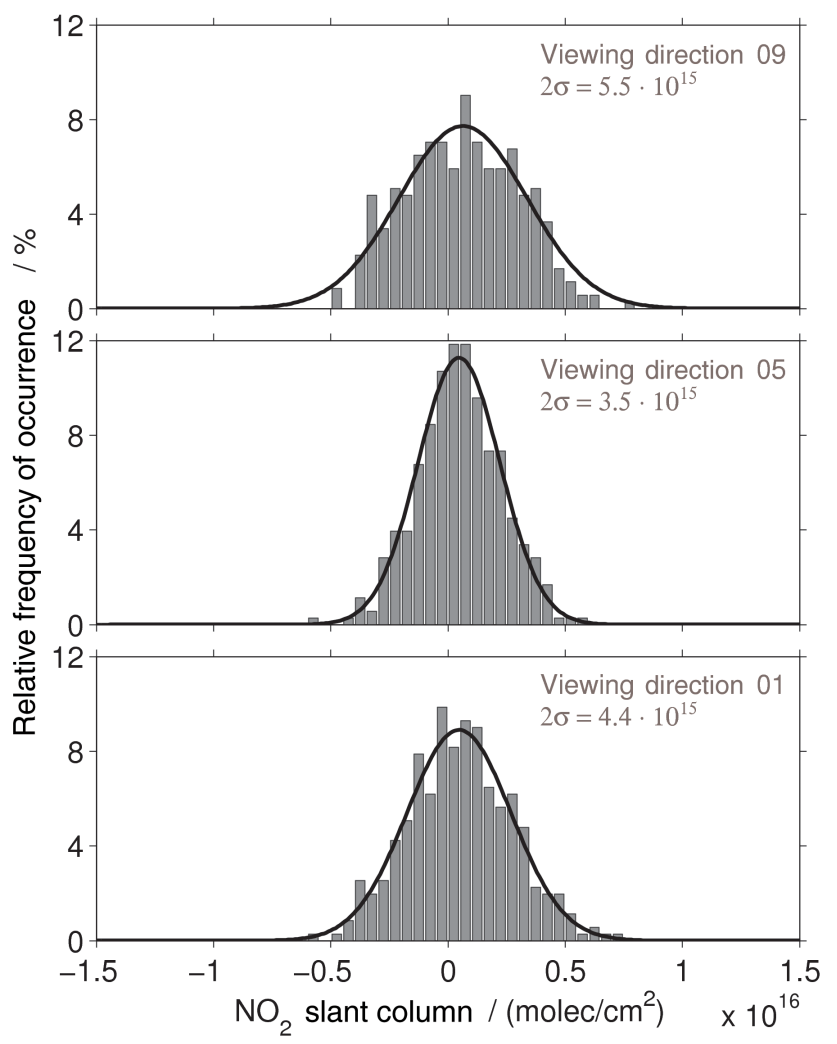

Figure 8. Histograms for the distribution and variability of $\mathrm{NO}_{2}$ amounts in three of the nine different viewing directions used for uncertainty analysis. Data used for this figure are recorded $3 \mathrm{~min}$ around the $1 \mathrm{~min}$ reference ( $I_{0}$ in the DOAS fit).

detection limit. Typical RMS values of the residual are in the range of $(1.5-2.0) \times 10^{-3}$. As the spectral sampling is larger than necessary, the RMS may be improved by coadding along the spectral axis. However, such a procedure has no effect on the noise of the retrieved $\mathrm{NO}_{2}$ amount.

The detection limits and uncertainties of the column results are better estimated from the retrieved $\mathrm{NO}_{2}$ amounts and their noise. For this purpose, the spread of $\mathrm{NO}_{2}$ values is analysed, taken from an area with small relative abundances (Platt and Stutz, 2008). In the present case, a suitable area is the reference location, from where the 1 min average reference spectrum $I_{0}$ for the DOAS analysis is obtained. For better statistics, a 3 min section from the flight is used for the error analysis. Figure 8 shows the results for viewing directions VD 01, 05 and 09. The relative occurrence of the given $\mathrm{NO}_{2}$ column densities is plotted in a histogram with a bin width of $0.5 \times 10^{15}$ molec cm${ }^{-2}$. The mean and the width of the distributions are found in each case by a fitted Gaussian function. The mean is slightly positive but close

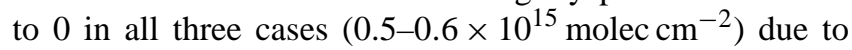
residual background $\mathrm{NO}_{2}$. With $95 \%$ probability, values lie within 2 times the standard deviation, $2 \sigma$, of $4.4,3.5$ and $5.5 \times 10^{15} \mathrm{molec} \mathrm{cm}^{-2}$ for VD 01,05 and 09 , respectively.

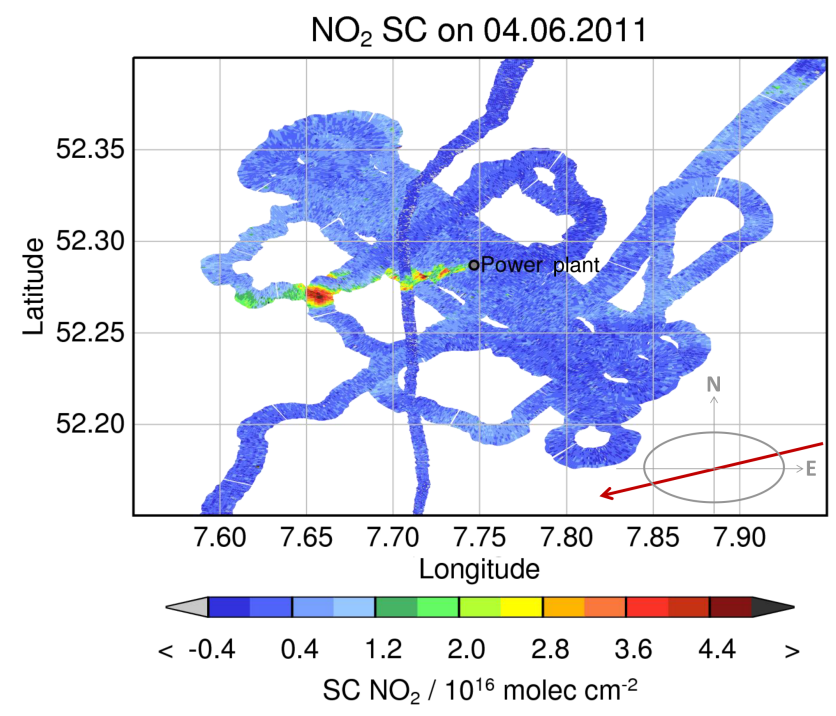

Figure 9. Map of $\mathrm{NO}_{2}$ slant columns measured during the flight on 4 June 2011 above the area around the Ibbenbüren power plant. The elevated levels of $\mathrm{NO}_{2}$ are clearly visible in the exhaust plume downwind of the power plant stack. In the bottom right corner of the map, the wind direction is indicated.

These values give a meaningful measure for the slant column detection limit and uncertainty for individual detections. With typical air mass factors of around 2.2 (Sect. 6.3), the vertical column detection limit and uncertainty lie between 1.6 and $2.5 \times 10^{15} \mathrm{molec} \mathrm{cm}^{-2}$ for a single observation, assuming a normal distribution and using $2 \sigma$ to cover the range of possible values. As a result of some real variability in the $\mathrm{NO}_{2}$ amounts, these values represent an upper limit of the experimental uncertainty.

At a typical speed of $60 \mathrm{~m} \mathrm{~s}^{-1}$ and $1100 \mathrm{~m}$ flight altitude, averaging over four subsequent measurements leads to nearly quadratic ground scenes with an area of $110 \times 120 \mathrm{~m}$, and the fit RMS is improved by nearly a factor of 2 as expected. In areas affected by anthropogenic activities, $\mathrm{NO}_{2}$ enhancements are clearly above the detection limit of the AirMAP instrument.

For the central flight pattern above the power plant area, the map in Fig. 9 shows the spatial distribution of $\mathrm{NO}_{2}$ slant column amounts. The column density is colour-coded according to the legend given in the map. For the analysis of the AirMAP observations no post-processing in the form of destriping has been applied. Such a procedure would be necessary in case of irregular viewing angle dependencies in the trace gas results, i.e. non-uniformities in the slant column values (Dobber et al., 2008; Popp et al., 2012). The LOS correction applied in the next section takes into account only the smooth viewing angle dependency due to a slightly longer light path for observations at the sensor edges. The single viewing directions of AirMAP yield consistent results, which do not exhibit stripy features, i.e. in the sense that certain 


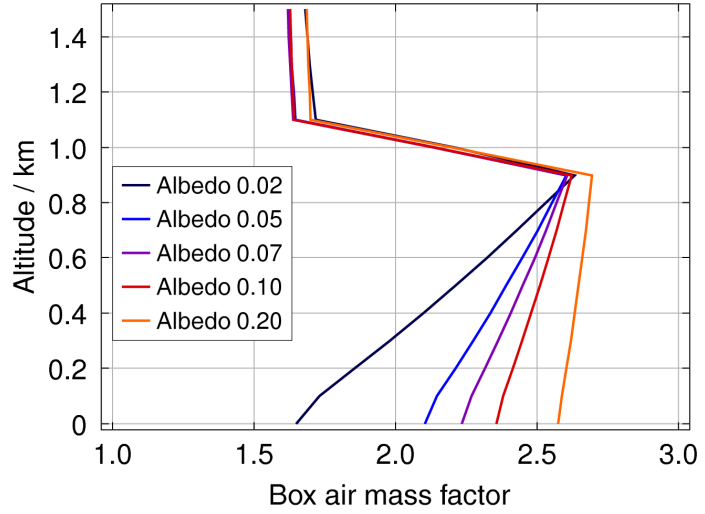

Figure 10. Box-air-mass-factors for $\mathrm{NO}_{2}$ calculated with SCIATRAN for flight geometries, $1.1 \mathrm{~km}$ flight altitude, $40^{\circ} \mathrm{SZA}$ and different ground reflectance values.

viewing directions would have the tendency to always show larger values than others, neither in the instrument calibration parameters nor in the retrieved $\mathrm{NO}_{2}$ column amount.

The location of the power plant is marked in the figure by a black dot. Enhanced amounts of $\mathrm{NO}_{2}$ are observed downwind of the power plant stack, while surrounding areas have much lower $\mathrm{NO}_{2}$ amounts than within the exhaust plume. The average wind direction is indicated in the map (see also Sect. 7.1). For single measurements, maximum slant columns reach $5.0 \times 10^{16}$ molec $\mathrm{cm}^{-2}$. Typical amounts within the power plant plume are between 1.2 and $4 \times 10^{16}$ molec $\mathrm{cm}^{-2}$. This is much smaller than values measured by Heue et al. (2008) above the huge South African Highveld power plants. In comparison, they observe slant columns up to $1.1 \times 10^{17}$ molec $\mathrm{cm}^{-2}$ for the coal and syngasfired Majuba power station (around $4100 \mathrm{MW}$ nominal capacity), and Melamed et al. (2003) observe vertical columns of up to $8 \times 10^{16} \mathrm{molec}^{-2}$ above the lignite-fired Monticello power station (Texas, USA, around $2000 \mathrm{MW}$ nominal capacity).

\subsection{Air mass factors for tropospheric $\mathrm{NO}_{2}$}

In order to transfer the retrieved $\mathrm{NO}_{2}$ slant columns into vertical column amounts, air mass factors (AMF) are computed by radiative transfer (RT) calculations. For this purpose, the SCIATRAN code is used (Rozanov et al., 2002). The AMF takes care of the relative light path length through the absorber layer, and the vertical column (VC) is determined by

$\mathrm{VC}=\frac{\mathrm{SC}}{\operatorname{AMF}(p)}$

The AMF depends on a set of parameters $p$ which determine the radiative transfer scenario. This is influenced, e.g. by the wavelength, ground reflectance, the absorber profile, SZA and aerosols. The sensitivity of the measurements in dependence of the altitude location of the absorber is given

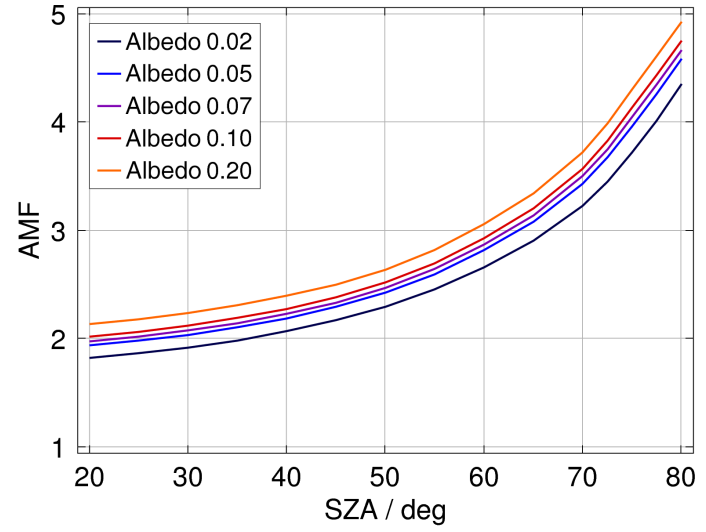

Figure 11. Air mass factors for $\mathrm{NO}_{2}$ and their SZA dependence for different ground reflectance values for a $\mathrm{NO}_{2}$ box profile of a mixed layer in the lowest $1 \mathrm{~km}$.

by the Box-AMF, which is the respective AMF in a defined altitude range. For a scenario of $40^{\circ} \mathrm{SZA}$ and a wavelength of $425 \mathrm{~nm}$, the Box-AMF is plotted in Fig. 10 for different values of the ground reflectance and considering a flight altitude of $1100 \mathrm{~m}$ and direct nadir LOS. SZA values for the campaign flight lie between 32 and $57^{\circ}$, and for the central flight pattern, between 39 and $50^{\circ}$. The flight took place on a clear summer day with good visibility; i.e. aerosols are not considered in these examples. The measurement sensitivity changes from 2.6 directly below the aircraft to values between 2.55 (20\% albedo) and 1.65 (5\% albedo) close to the ground. The sensitivity for $\mathrm{NO}_{2}$ observation therefore depends on the trace gas altitude profile.

The path length of solar electromagnetic radiation through the layers below the aircraft also depends on the respective viewing angle, which for the AirMAP instrument reaches up to $\pm 24^{\circ}$ for level flight and even larger angles when the aircraft is banking and turning. The LOS influence on the AMF determined by RT calculations is only slightly different $(<1 \%)$ from the geometrically calculated factor. The AMF for nadir view $\left(\mathrm{AMF}_{0}\right.$ for $\left.\operatorname{LOS} \alpha=0^{\circ}\right)$ is computed with SCIATRAN, and the correction for LOS angle $\theta_{i}$ is then based on the geometric AMFs, $\widehat{\mathrm{AMF}}_{0}$ and $\widehat{\mathrm{AMF}}_{\theta_{i}}$. With SZA $\theta_{\mathrm{s}}$ and $\operatorname{LOS} \theta_{i}$, the corrected $\mathrm{VC}_{\theta_{i}}$ for slant viewing directions is determined by

$\mathrm{VC}_{\theta_{i}}=\mathrm{SC}_{\theta_{i}} \cdot \frac{1}{\mathrm{AMF}_{\theta_{i}}} \approx \mathrm{SC}_{\theta_{i}} \cdot \frac{1}{\mathrm{AMF}_{0}} \cdot \frac{\widehat{\mathrm{AMF}}_{0}}{\widehat{\mathrm{AMF}}_{\theta_{i}}}$

with the geometric air mass factor

$\widehat{\mathrm{AMF}}_{\theta_{i}}=\frac{1}{\cos \left(\theta_{\mathrm{s}}\right)}+\frac{1}{\cos \left(\theta_{i}\right)}$.

For evaluations of the observed $\mathrm{NO}_{2}$ and calculation of $\mathrm{VC}$ amounts, a boundary layer box profile of well-mixed $\mathrm{NO}_{2}$ in the lowest $1 \mathrm{~km}$ altitude is assumed, and the albedo is set to 

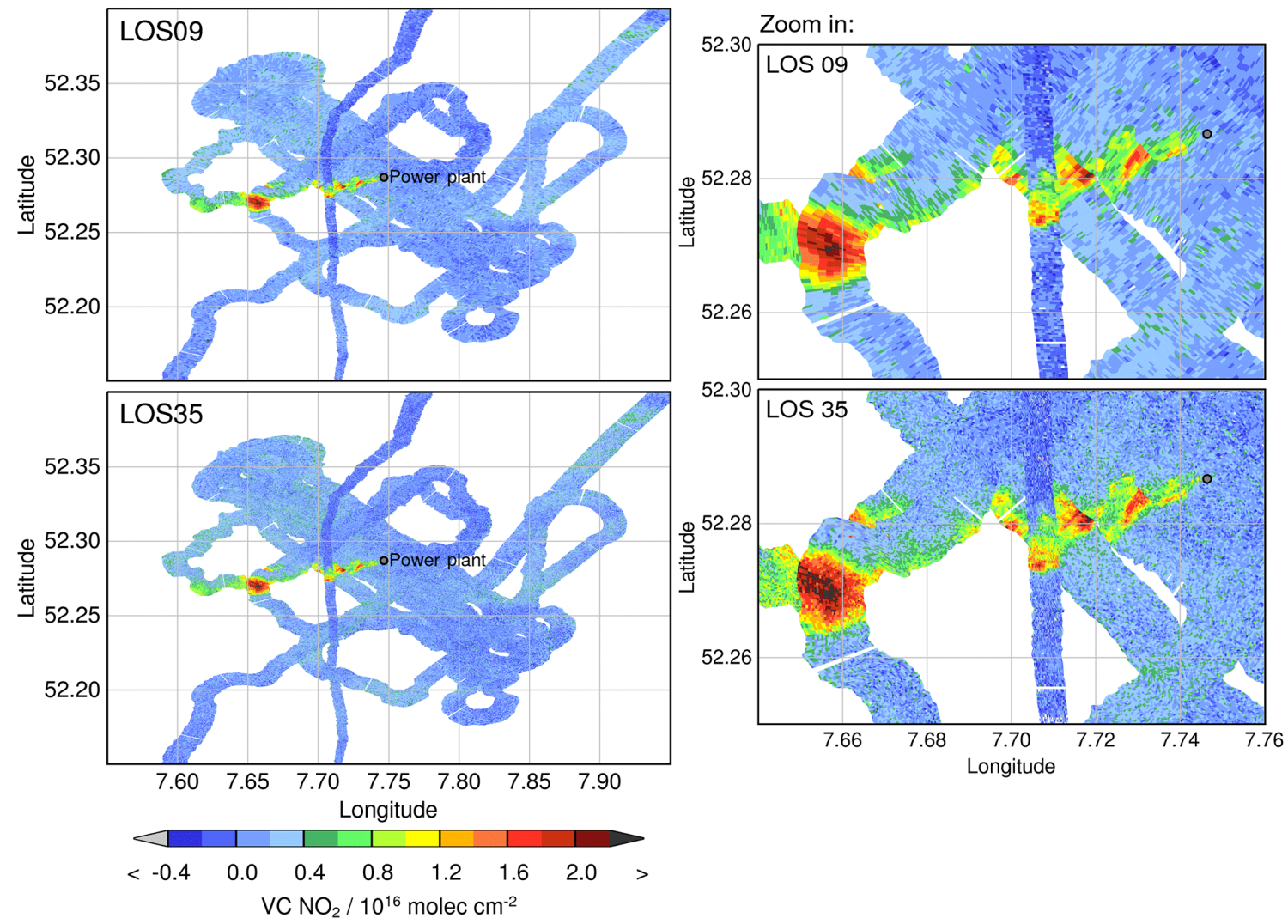

Figure 12. Map of $\mathrm{NO}_{2}$ vertical columns above the Ibbenbüren power plant exhaust plume for division of the field of view into 9 LOS (top) and 35 LOS (bottom). On the right, a close-up view is shown. The retrieved slant columns from Fig. 9 and AMF from Fig. 11 (albedo 0.05 , blue curve) have been used. Good consistency of $\mathrm{NO}_{2}$ amounts is achieved independent of the LOS division.

$5 \%$. In the vicinity of emission sources, the $\mathrm{NO}_{2}$ will not be well mixed below the aircraft. Using Gaussian plume dispersion, corresponding vertical profiles within an exhaust plume have been computed, and differences between plume profile AMFs and the Box-AMF have been investigated. The AMF for a plume at $6 \mathrm{~km}$ distance used below for emission estimates (Sect. 7) differs less than a few percent from the Box-AMF within the relevant SZA range, whereas for profiles closer to the emitting stack, the plume is more confined and may cause a difference of about $5 \%$ in the AMF.

It is worth noting that neither SCIATRAN nor the geometric approximation take 3-D effects into account. The importance of such 3-D effects increases for increasing SZA, increasing LOS angle and for a plume which is horizontally confined as well as situated at high altitudes directly below the aircraft. For such a case, an individual light beam may travel through the plume only once, e.g. either on the way from sun to the ground or from the ground to the instrument. In this case, the AMF would be overestimated and the resulting vertical column would be underestimated. In addition, the assignment of the measured trace gas amount to the ground pixel may be affected. Multiple scattering, however, reduces the influence of 3-D effects.
Close to the stack, 3-D effects might be present in our case; further away from the stack, however, the plume has already spread in horizontal and vertical directions, so that the influence of 3-D effects becomes less relevant.

\section{4 $\mathrm{NO}_{2}$ vertical columns}

The same observations as in Fig. 9 with nine viewing directions are depicted in Fig. 12 (top) now for the $\mathrm{NO}_{2}$ vertical columns in the area of the Ibbenbüren power plant. In order to assess the capability of AirMAP of monitoring $\mathrm{NO}_{2}$ columns at even better spatial resolution, the full 35 viewing directions have been analysed individually (LOS35 retrieval). For direct comparison, the full resolution retrieval result is plotted right below in Fig. 12 (bottom). The resulting $\mathrm{NO}_{2}$ column amounts from the two different resolution cases are consistent. Consistency has been checked also by comparing the $\mathrm{NO}_{2} \mathrm{VC}$ in one viewing direction from the LOS09 retrieval with the average of the contributing viewing direction from the LOS35 retrieval. For example, comparing VD 09 of the LOS09 retrieval to the average of VD 32 to 35 of the full resolution LOS35 retrieval, the difference is as 
small as $0.4 \pm 8.5 \times 10^{14}$ molec $\mathrm{cm}^{-2}$ within the central flight pattern.

The $\mathrm{VC}$ amounts of $\mathrm{NO}_{2}$ are strongly enhanced within a confined plume downwind of the power plant stack, as seen before. Maximum VC amounts reach up to $2.4 \times$ $10^{16}$ molec $\mathrm{cm}^{-2}$, while typical values within the exhaust plume lie between 0.6 and $2.0 \times 10^{16}$ molec $\mathrm{cm}^{-2} \cdot \mathrm{NO}_{2}$ amounts in overpasses closer to the stack are lower than in the overpasses further downwind, because emissions of nitrogen oxides first occur as $\mathrm{NO}$ which is converted into $\mathrm{NO}_{2}$ during the transport in the plume. The most distant overpass at around $6 \mathrm{~km}$ reveals the largest $\mathrm{NO}_{2}$ amounts. In addition, the plume broadens while it is transported away from the stack, and the integrated $\mathrm{VC}$ across the plume increases with distance from the stack. This is shown in more detail in the following section. In comparison to the $\mathrm{NO}_{2}$ amounts within the plume, surrounding $\mathrm{NO}_{2}$ values are rather small and variable below $(4 \pm 2) \times 10^{15} \mathrm{molec} \mathrm{cm}^{-2}$.

One flight segment in a north-south direction shows lower $\mathrm{NO}_{2}$ amounts than the other flight paths. The respective segment was flown latest in the pattern and at lower altitude; therefore the track is rather narrow. The later time means that the SZA and the influence of stratospheric $\mathrm{NO}_{2}$ have changed. This effect is noticeable but is too small to entirely explain the observed change in the background $\mathrm{NO}_{2}$. The lower flight altitude might cause some $\mathrm{NO}_{2}$ to be missed by the measurements. Additional effects probably influence the measurements in this flight path, which is however not further used in this study.

Figure 12 demonstrates some further features of the imaging DOAS aircraft measurements. A comparably large area is covered with trace gas observations within a relatively short time interval at fine spatial resolution. The flight pattern above the target area with several partly overlapping flight legs was, e.g. completed within about $80 \mathrm{~min}$. Hence, the observations with AirMAP are useful for the analysis of smallscale trace gas variability above extended areas with several tens of kilometres' side length.

\section{Power plant emissions}

The $\mathrm{NO}_{2}$ plume is investigated during several overpasses. In Fig. 13, five overpasses over the exhaust plume are displayed. They show the $\mathrm{NO}_{2}$ measurements at different distances downwind of the power plant stack. The overpass furthest away has a distance of around $6 \mathrm{~km}$ from the stack and is used for an emission estimate. Many details in the plume structure are resolved by the AirMAP measurements. At 09:40 UTC close to the stack, $\mathrm{NO}_{2}$ amounts are still rather low, as $\mathrm{NO}_{2}$ needs time to form from $\mathrm{NO}$ and ozone. Especially the two overpasses at 09:52 and 10:00 UTC show that the plume structure is strongly inhomogeneous. At 09:52 UTC the largest $\mathrm{NO}_{2}$ amounts are not found in the lateral centre but towards the southern edge of the plume. At 10:00 UTC

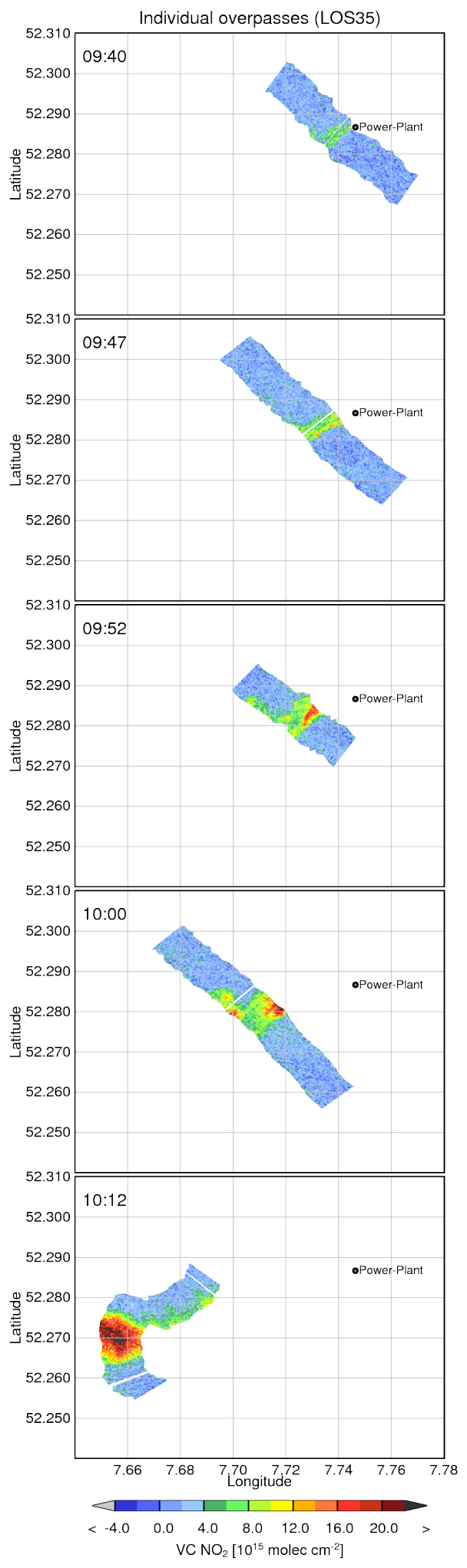

Figure 13. Overpasses at five different times between 09:40 and 10:12 UTC over the $\mathrm{NO}_{2}$ plume. Data from the LOS35 analysis are shown. The latest overpass at 10:12 UTC has a distance of around $6 \mathrm{~km}$ from the power plant and is used for the emission flux calculation. 


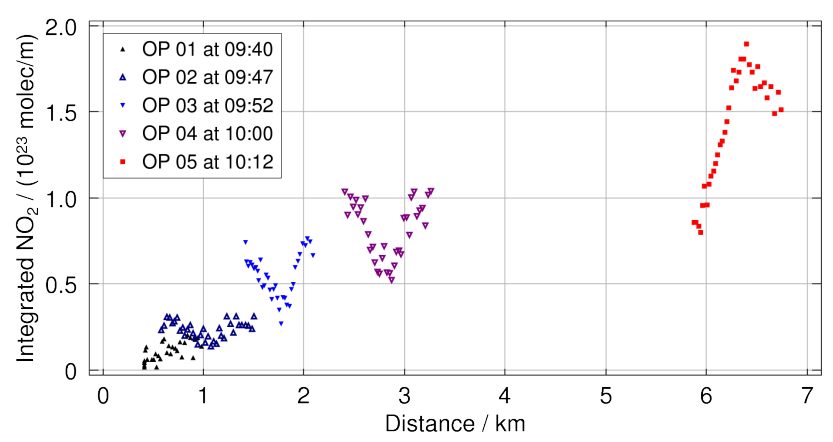

Figure 14. Integrated $\mathrm{NO}_{2}$ amount across the plume from five individual overpasses (OP) at different times and distances from the stack. Results are taken from the LOS35 evaluation; therefore, in total, 175 cross sections through the plume are included in this diagram.

an interruption of the plume in wind direction (across track), i.e. a discontinuity due to atmospheric turbulence, is observed. Figure 14 shows the integrated $\mathrm{NO}_{2}$ amount across the plume with respect to the distance of the stack. The integrated $\mathrm{NO}_{2}$ amount (line integral) takes into account the relative angle between the cross section and the direction of the plume movement, i.e. the wind direction; see discussion below. Cross sections of the five overpasses are included in this figure, and data are based on the LOS35 evaluation. In total, the results from 175 cross sections are shown. The detailed maps of the plume and the integrated $\mathrm{NO}_{2}$ amounts show that emission estimates from single cross sections would lead to fairly different results. $\mathrm{NO}_{2}$ emission rates $Q$ from the power plant point source are derived using the fifth cross section from the overpass furthest away from the stack. For this purpose, Gauss's divergence theorem is utilized, describing the relation between the flux of a vector field through a closed surface (which is measured) to the divergence of the vector field inside the enclosed volume (which relates to the source strength). This relationship has also been used, e.g. by Wang et al. (2006), Heue et al. (2008) and Krings et al. (2013). Local wind data are a prerequisite for the emission calculations.

\subsection{Wind data}

Information on wind speed and direction is received from the COSMO-DE regional model from the German Weather Service DWD (Doms and Baldauf, 2015). Observational data are assimilated, and the output grid size is $2.7 \times 2.7 \mathrm{~km}^{2}$. The altitude grid has 12 levels in the lowest kilometre. For the closest grid points around the target area, wind profiles (speed and direction) have been extracted. The wind speed on the campaign day was moderate, increases with altitude in the boundary layer and drops to smaller values above. Figure 15 shows the altitude profile of the wind speed (left) and direction (middle) for a location close to the power plant $\left(7.67^{\circ} \mathrm{E}\right.$, $52.28^{\circ} \mathrm{N}$ ) for three hourly time steps at 09:00, 10:00 and

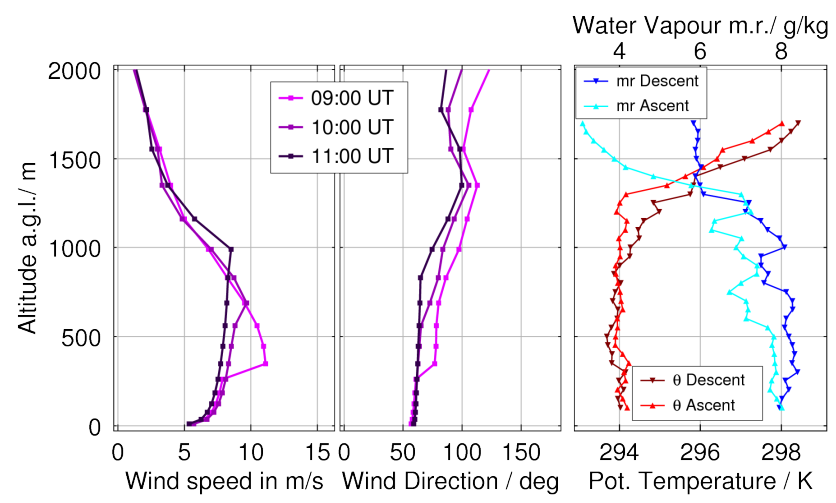

Figure 15. Example vertical profiles of wind speed (left) and wind direction (middle) from the COSMO-DE model on 4 June 2011 at three time steps (09:00, 10:00 and 11:00 UTC) for the location $7.67^{\circ} \mathrm{E}, 52.28^{\circ} \mathrm{N}$, close to the Ibbenbüren power station, as well as potential temperature $\Theta$, and water vapour mixing ratio m.r., during a dive south of the power plant (right).

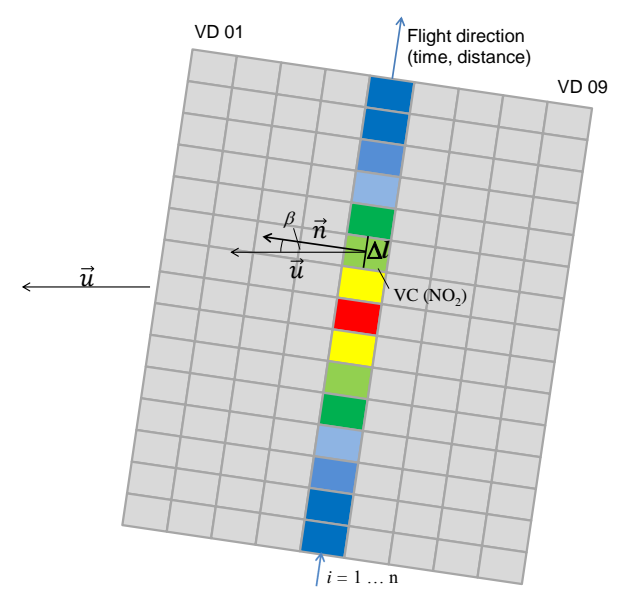

Figure 16. Sketch illustrating the emission flux calculation from AirMAP data for an example plume overpass with wind vector $\boldsymbol{u}$, line element $\Delta l$, flight path normal vector $\boldsymbol{n}$, angle $\beta$ and $\mathrm{NO}_{2}$ vertical column $\mathrm{VC}\left(\mathrm{NO}_{2}\right)$. The contributions $i$ to the emission source strength $Q$ (Eq. 11) are summed up along the transect.

11:00 UTC. Vertical changes in wind speed and direction are less pronounced at plume overpass time after 10:00 UTC than earlier in the morning. The diagram on the right shows measurements of moisture mass mixing ratio (m.r.) and potential temperature $\Theta$. These measurements were taken about $15 \mathrm{~km}$ south of the example plume overpass during a descent into a regional airport at around 10:46 UTC. For each parameter, two curves for the descent and the subsequent ascent are shown. The potential temperature as well as the moisture profile is fairly constant within the mixed layer, while vertical gradients increase strongly above. From these measurements, a mixing layer height of about $1300 \mathrm{~m}$ is estimated, and spreading of the $\mathrm{NO}_{2}$ plume takes place in this altitude range. 
Assuming Gaussian plume dispersion for the shape and development of the $\mathrm{NO}_{2}$ emission plume emerging at the stack altitude of $275 \mathrm{~m}$ a.g.l., the vertical plume extent can be estimated. Considering that the atmospheric stability class valid for the present campaign day was rated as slightly unstable (Krings et al., 2013), dispersion leads to a substantial spreading of several hundred metres within the boundary layer at a distance of $6 \mathrm{~km}$ from the stack. From this perception and the measurements of the vertical mixing layer extent, a homogeneous distribution of $\mathrm{NO}_{2}$ below the aircraft is assumed for the wind averaging at this location. Below the aircraft, the wind speed varies between 6.1 and $9.2 \mathrm{~m} \mathrm{~s}^{-1}$ with an average of $8.3 \mathrm{~m} \mathrm{~s}^{-1}$. A small bias of $+0.7 \mathrm{~m} \mathrm{~s}^{-1}$ in the COSMO-DE wind speed data for the respective time and region has been identified by Krings et al. (2013) in comparison to the AIMMS-20 wind probe. Taking the bias into account, a wind speed of $7.6 \mathrm{~m} \mathrm{~s}^{-1}$ is used. The wind direction varies between 61 and $75^{\circ}$ with an average of about $68^{\circ}$. The AIMMS-20 wind probe on the aircraft yields a direction of $78^{\circ}$ which is turned clockwise at the higher altitude of the aircraft position above the plume in agreement with the COSMO-DE profiles. The apparent plume transport from the measurements is consistent with a wind direction of around $70^{\circ}$. For calculations, the $68^{\circ}$ angle is used, and uncertainties on this value are around $\pm 5^{\circ}$.

\subsection{Calculation and discussion of the emission rate}

The aircraft measurements integrate over the vertical dimension, so that the flux calculation considers the horizontal component $\boldsymbol{F}=\mathrm{VC} \cdot \boldsymbol{u}$ of the $3-\mathrm{D}$ vector field of $\mathrm{NO}_{2}$ transport. VC is the $\mathrm{NO}_{2}$ vertical column and $\boldsymbol{u}$ is the effective horizontal wind vector. The source strength (emission rate) $Q$ is thus determined from the vertical $\mathrm{NO}_{2}$ columns measured within the exhaust plume. The divergence theorem yields

$Q=\int_{A} \nabla \boldsymbol{F} \mathrm{d} A=\oint_{L}(\boldsymbol{F} \cdot \boldsymbol{n} \mathrm{d} l)=\oint_{L} \mathrm{VC} \cdot \boldsymbol{u} \cdot \boldsymbol{n} \mathrm{d} l$.

The integral runs over an area $A$ enclosed by the surrounding line $L$. The calculated flux thus contains the emissions from all sources enclosed by $L$. For calculation of $Q$ from the experimental discrete data, the integral in Eq. (9) converts into a sum over the observed ground pixels $i$ :

$$
\begin{aligned}
Q & =\oint_{L} \mathrm{VC} \cdot \boldsymbol{u} \cdot \boldsymbol{d} \boldsymbol{l} \approx \sum_{i} \mathrm{VC}_{i} \cdot \boldsymbol{u} \cdot \Delta \boldsymbol{l}_{i} \\
\Rightarrow Q & =\sum_{i} \mathrm{VC}_{i} \cdot u \cdot \Delta l_{i} \cos (\beta) .
\end{aligned}
$$

In the last step, $\beta$ is the angle between the wind vector $\boldsymbol{u}$ and the normal vector $\boldsymbol{n}$ of the line element along flight direction $\Delta \boldsymbol{l}$ (or along any other selected transect). The product vanishes for pieces of the boundary $L$ which are parallel to

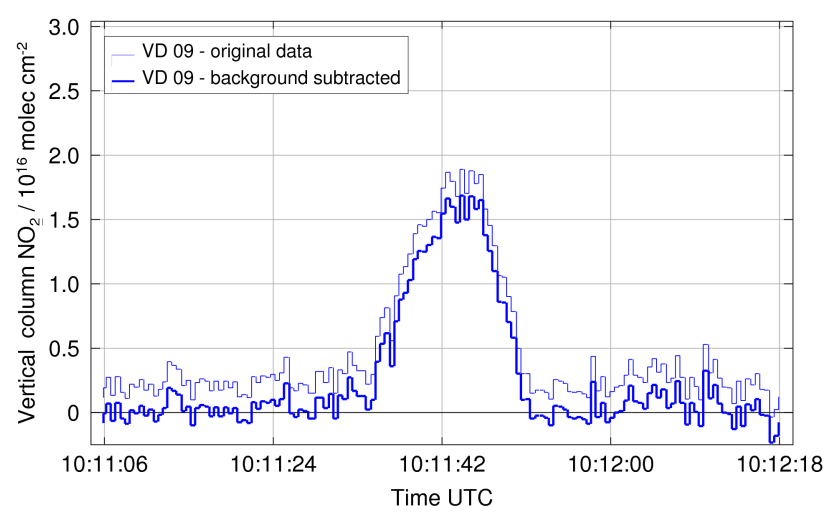

Figure 17. Cross section of $\mathrm{NO}_{2}$ vertical columns through the exhaust plume at around 10:12 UTC and a distance of around $6 \mathrm{~km}$ from the power plant used for the emission flux calculation. The cross section is taken from the ninth viewing direction of the LOS09 analysis.

the wind direction. Figure 16 illustrates the determination of $Q$ from the aircraft measurements with a simplified sketch of a plume overpass, including the parameters that enter the above calculation. When closing the integral over the surrounding line around the power plant on the upwind side of the power plant, positive $\mathrm{NO}_{2}$ amounts lead to a reduction of the resulting emission rate as the wind and line normal vectors are antiparallel.

The cross section through the plume along flight direction for one example viewing direction (VD 09 from the LOS09 retrieval) is seen in Fig. 17. The cross section shows enhanced $\mathrm{NO}_{2}$ amounts at around 10:12 UTC up to $1.9 \times 10^{16} \mathrm{molec}^{-2}$, clearly above the background amount in a compact shape. Immediately to the sides of the central plume, a mean vertical $\mathrm{NO}_{2}$ column of $\mathrm{VC}_{\mathrm{B}}=$ $2 \times 10^{15}$ molec cm $^{-2}$ is observed, resulting from background $\mathrm{NO}_{2}$ concentrations and outflow from the city of Ibbenbüren. Parts of the city of Ibbenbüren are close to the power plant and are therefore enclosed by any possible flight path. The additional sources can influence the emission estimate if the closed line integral is determined. Alternatively, the background $\mathrm{NO}_{2}$ is assumed constant across the plume and subtracted from the observed $\mathrm{NO}_{2}$ in order to effectively remove additional emission sources. The emission rate is then determined by the downwind part of the line integral over the background corrected $\mathrm{NO}_{2}$ column $\mathrm{VC}-\mathrm{VC}_{\mathrm{B}}$. Calculated this way, the emission rate is slightly smaller than from the closed integral; however, the differences are not significant. Other local sources can therefore be concluded to be small. Figure 18 shows the computed emission rates with respect to the distance from the power plant location for the nine viewing directions, i.e. nine independent results for $Q$. From this, the average emission rate and standard deviation is $\bar{Q}=(1.1 \pm 0.3) \times 10^{24}$ molec s$^{-1}$. The standard deviation of the derived values for $Q$ is of the same magnitude as the error 


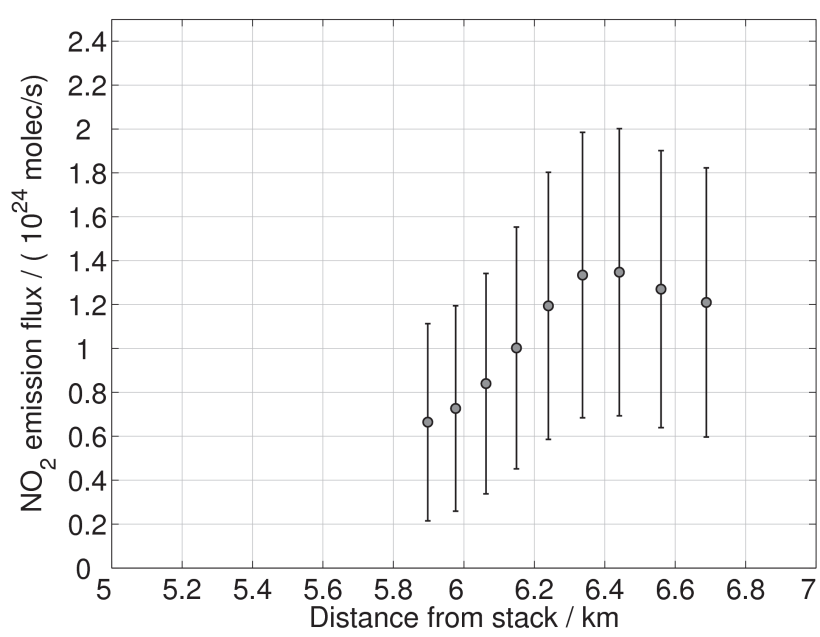

Figure 18. Emission flux estimates from the plume overpass at around $6 \mathrm{~km}$ distance for the nine different viewing directions.

of the mean when considering the uncertainties on the individual results of $Q$. The uncertainties on all involved quantities making up for the error bars in Fig. 18 are discussed in Sect. 8 below.

\subsection{Comparison to emission reports}

The determined emission rates correspond to $82 \pm 20 \mathrm{~g} \mathrm{~s}^{-1}$ $\mathrm{NO}_{2}$. For the conversion into a $\mathrm{NO}_{x}$ emission rate, a value for the $[\mathrm{NO}] /\left[\mathrm{NO}_{2}\right]$ ratio $r$ needs to be assumed. The ratio $r$ is the inverse of the well-known "Leighton ratio", which is the ratio $\left[\mathrm{NO}_{2}\right] /[\mathrm{NO}]$ in photo-stationary state. The $\mathrm{NO}_{x}$ emission rate $Q_{\mathrm{NO}_{x}}$ is then given by

$Q_{\mathrm{NO}_{x}}=(1+r) \cdot Q_{\mathrm{NO}_{2}}$.

A value of $r=0.25$ is used (Ehhalt et al., 1992), which is reasonable as soon as steady state is achieved; see discussions below. Following from this, the $\mathrm{NO}_{x}$ emission rate $Q_{\mathrm{NO}_{x}}$ is $103 \pm 25 \mathrm{~g} \mathrm{~s}^{-1} \mathrm{NO}_{x}$ in mass of $\mathrm{NO}_{2}$. The error does not include uncertainties of the ratio $r$. Reports issued in the EPRTR state an emission rate of $3060 \mathrm{ta}^{-1} \mathrm{NO}_{x}$ in mass of $\mathrm{NO}_{2}$. Extrapolating the instantaneous observations from the individual overflight to an entire year, the observed annual emission rate would be $3240 \pm 800 \mathrm{ta}^{-1}$, consistent with the reported amounts. The extrapolation is only reasonable either if the emission rate is constant over the course of the year, or if the individual day was a representative situation of typical conditions, which is both not necessarily the case. However, the comparison shows that the plume estimate of $\mathrm{NO}_{x}$ emissions and the reported annual average are consistent.

\subsection{Limitations of the emission calculations}

At example locations closer to the stack, the analysis leads to lower $\mathrm{NO}_{x}$ emission rates. The reason for this is that less of the emitted $\mathrm{NO}$ has been converted to the measured $\mathrm{NO}_{2}$
(Davis et al., 1974). For application of the divergence theorem, chemical inertness of the compound or a stationary state condition needs to be assumed. However, $\mathrm{NO}_{2}$ is not inert at atmospheric conditions. For a meaningful reasoning, the distance of the $\mathrm{NO}_{2}$ measurement from the power plant needs to be sufficiently large so that the photochemical stationary state can be assumed as implied above. Stationary state will evolve over the first few tens of kilometres of an exhaust plume (Davis et al., 1974). The actual distance required depends on wind speed and atmospheric stability as well as chemical conversions mainly driven by reactions with $\mathrm{O}_{3}$ and photolysis. Wind speed is moderate, and at around $6 \mathrm{~km}$ distance, an air parcel has travelled for nearly $15 \mathrm{~min}$ from the stack. At large $\mathrm{NO}$ concentrations, $\mathrm{O}_{3}$ can be entirely depleted in the plume centre. $\mathrm{NO}_{x}$ emissions are smaller in the present case as compared to Davis et al. (1974). If $\mathrm{O}_{3}$ is not entirely depleted, conversion to $\mathrm{NO}_{2}$ and achievement of a steady state evolves faster. If a steady state has not been reached, the factor $r$ and hence also $Q_{\mathrm{NO}_{x}}$ would be larger than estimated above. In conclusion, estimates of the $\mathrm{NO}_{x}$ emission rate are derived here under these limitations.

\subsection{Non-uniform plume dispersion}

The $\mathrm{NO}_{2}$ amounts within the emission plume do not show a smooth and uniform distribution. The emission rates plotted in Fig. 18 represent nine independent results for $Q$ at different distances from the stack, i.e. different times since emission. The approximate time difference between two adjacent viewing directions, taking the locations and wind speed into account, is about $13 \mathrm{~s}$; the difference between the outermost directions is about $2 \mathrm{~min}$. Even from this short excerpt of the emission plume, its variability becomes clear. Possibly the NO emissions in the first place, but mainly the chemical conversions and the transport process are presumably nonuniform. The particularly inhomogeneous structure of the plume was addressed in Figs. 13 and 14, where overpasses closer to the stack are included as well. In this respect, observations made with the AirMAP instrument provide a good opportunity to study these plume processes within short time and spatial scales and covering distances of many kilometres.

\section{Error estimates}

In the calculation of the $\mathrm{NO}_{2}$ emission estimates, the following uncertainties and errors are considered. All quantities from Eq. (11) contribute to the error budget, that is the retrieved $\mathrm{NO}_{2} \mathrm{VC}$ depending on the $\mathrm{SCs}$ from the DOAS retrieval and the considered AMF, the line element $\Delta l$ depending on GPS coordinates and aircraft angles, as well as the wind speed and angle $\boldsymbol{u}$ and $\beta$. The fact that the emission calculation comprises the subtraction of the background amount of $\mathrm{NO}_{2}$ shows that (a) the uncertainty of the $\mathrm{NO}_{2}$ background column amount plays a role, while (b) the choice 
of the reference location for the reference spectrum $I_{0}$ in the DOAS retrieval does not affect the emission calculation, and hence also not its uncertainty. From all considered error sources, an overall relative and additional absolute uncertainty of around $\pm 30 \%$ and $\pm 2.5 \times 10^{23}$ molec s$^{-1}$, respectively, is determined for the instantaneous emission rate $Q_{\mathrm{NO}_{2}}$.

\subsection{Uncertainties of the vertical $\mathrm{NO}_{2}$ columns}

The $\mathrm{NO}_{2}$ DOAS retrieval exhibits fitting errors around $5 \%$ for large $\mathrm{NO}_{2}$ values within the plume. Naturally, the relative error becomes bigger for small $\mathrm{NO}_{2}$ abundances to the sides of the plume. Absolute errors lie in the range of $2 \times 10^{15}$ molec $\mathrm{cm}^{-2}$. The same absolute uncertainty applies for the background $\mathrm{NO}_{2}$ amount, determined next to the emission plume. Systematic errors induced by the choice of $\mathrm{NO}_{2}$ cross section are in the range of a few percent, e.g. the temperature dependence causes an uncertainty of $<2 \%$ for a temperature change from surface to $2 \mathrm{~km}$ of about $15 \mathrm{~K}$ (from 297 to $282 \mathrm{~K}$, based on COSMO-DE data), when using a $293 \mathrm{~K}$ reference cross section.

Main uncertainties of the $\mathrm{NO}_{2} \mathrm{VC}$ arise from assumptions necessary for the calculation of the AMF, e.g. through influences from aerosol scattering, the vertical $\mathrm{NO}_{2}$ profile and ground albedo. While aerosol above a remotely sensed $\mathrm{NO}_{2}$ layer tends to shield part of the trace gas, mixed aerosol with $\mathrm{NO}_{2}$ may also lead to enhanced sensitivity, e.g. shown for satellite-specific studies (Leitão et al., 2010). The campaign day was a fairly clear and sunny day with good visibility. Therefore, the error from assuming there to be no aerosol scattering in the radiative transfer is not large. Conversely to the $\mathrm{NO}_{2}$ vertical profile, which in general is not known, the emission plume injection height and the height of the mixed layer are approximately known. AMFs for different profiles, box-shaped and Gaussian plumes, as well as for different ground albedo values, have been computed (Sect. 6.3). From the related uncertainties, deviations of the AMF in the range of $25 \%$ are considered.

\subsection{Uncertainties of the path element length}

Factors influencing the calculation of the length of the path element in the line integral include the timing of the GPS signal, the uncertainties in the GPS positioning itself and in the aircraft orientation and altitude. In comparison to the precision and accuracy of the GPS position and its timing, which lead to an uncertainty of a few metres only, the influence of the aircraft angles are the dominant ones. Also, the inaccuracy of the altitude is small in comparison. Uncertainties in the pitch and roll angles, of around $0.5-1^{\circ}$ each, cause displacements on the ground, leading to an overall error of around $30 \mathrm{~m}$ for the geolocation in our case, i.e. when flying at the main altitude of around $1100 \mathrm{~m}$. However, it is the difference in geolocation between the start and end of the measurements that is entered in the emission calculation in Eq. (11), which causes a major part of the systematic uncertainty of the angles to be cancelled out. A curvature in the flight path during overpass (cf. Fig. 13) induces an inaccuracy as the path is approximated by straight segments leading to a systematic but small underestimation of the track length. Overall, the influence of the path length uncertainty is minor in comparison to the other error sources.

\subsection{Uncertainties of the wind speed and direction}

The wind speed and direction imply errors (a) due to uncertainties and inaccuracies in the model data itself, (b) due to the finite grid size and (c) due to uncertainties in the vertical expansion of the emission plume. Depending on the time of day and the lifting of the boundary layer, the variation of the wind speed and direction with altitude can be fairly strong. From estimates of the plume vertical location and extension, related uncertainties on the order of $10 \%$ for the wind speed and $5 \%$ on the cosine of relative wind angle $\beta$ are reasonable. The latter is true as long as $\beta<30^{\circ}$, which is the case for the analysed overpass.

\section{$9 \mathrm{NO}_{2}$ above motorways}

As the AirMAP instrument offers high spatial resolution and good quality $\mathrm{NO}_{2}$ measurements, it is worth investigating weaker and smaller $\mathrm{NO}_{2}$ sources. The flight path also followed motorways in north-west Germany. Figure 19 shows a flight section along the A1 motorway for about $5 \mathrm{~min}$ around 08:50 UTC. The recorded intensity is shown in the left map, where the motorway can clearly be distinguished by higher intensity values in comparison to surrounding vegetation, again demonstrating the good imaging capability of AirMAP. Some bright reflecting fields in the western part of the track yield even higher intensities than the road surface. The two maps on the right cover an excerpt of the section for the reflected intensity (top right) and the retrieved $\mathrm{NO}_{2}$ amounts (bottom right), all from the LOS35 retrieval. With a flight altitude of $1500 \mathrm{~m}$ and an airspeed of $90 \mathrm{~m} \mathrm{~s}^{-1}$, the individual ground pixel is $40 \times 45 \mathrm{~m}^{2}$ in across $\times$ along track size. Enhanced $\mathrm{NO}_{2}$ values of around $5 \times 10^{15}$ molec cm $\mathrm{cm}^{-2}$ are detected above the motorway. The AMF causes signal enhancement of the $\mathrm{NO}_{2}$ amounts above the bright surface due to an increased albedo and will need to be considered for more precise calculations. However, while the intensity (Int) is larger above the bright field than above the motorway, $\mathrm{NO}_{2}$ is only enhanced above the road. The following values are deduced from 23 observations (ground pixels) above the motorway and 30 observations above the bright field:

- for the motorway: $\mathrm{VC}=5 \pm 2 \times 10^{15}$ molec $\mathrm{cm}^{-2}$ and Int $=(14 \pm 2) \times 10^{3}$ counts s $^{-1}$;

- for the bright field: $\mathrm{VC}=2 \pm 1 \times 10^{15}$ molec $\mathrm{cm}^{-2}$ and Int $=(17 \pm 3) \times 10^{3}$ counts $\mathrm{s}^{-1}$. 
The enhanced reflectivity from the road surface is therefore not sufficient to explain the retrieved $\mathrm{NO}_{2}$ amounts. In conclusion, enhanced $\mathrm{NO}_{2}$ from motor vehicle emissions from the motorway is clearly observed.

In previous studies, Pundt et al. (2005) used a tomographic DOAS approach to measure $\mathrm{NO}_{2}$ emissions from a German motorway, the A656, at a fixed ground location. This study was used in order to compare the order of magnitude of $\mathrm{NO}_{2}$ column amounts for a medium-sized highway. They found enhancement of $\mathrm{NO}_{2}$ on the order of 5-10 ppb above the background level in the lowest few tens of metres, with measurement data being collected between the surface and $40 \mathrm{~m}$ altitude. By vertically integrating these numbers, the column amount is around $0.4-0.8 \times 10^{15}$ molec cm $^{-2}$ above background. $\mathrm{NO}_{2}$ amounts decrease with altitude, but any $\mathrm{NO}_{2}$ present at higher altitudes originating from the traffic emissions is not included. Following the Federal Highway Research Institute (Bundesanstalt für Straßenwesen, BASt), the vehicle number frequencies for the respective motorway sections of the A656 and A1, respectively, are both in the same range of around 55000 vehicles on average in $24 \mathrm{~h}$ when considering both travel directions (http://www.bast.de, last visited 19 December 2013). The above observations from aircraft yield a column of $3.0 \pm 2.2 \times 10^{15}$ molec cm $\mathrm{cm}^{-2} \mathrm{NO}_{2}$ above background for the A1, which is larger than that from the tomographic experiment over the A656, but lies in a comparable and reasonable range. The difference is a result of the typically strong variations in time of the instantaneous traffic densities and flow, and is also influenced by the vertical confinement of the A656 data used here from Pundt et al. (2005). It is relevant to add that an overestimation of the $\mathrm{NO}_{2}$ vertical column from the AirMAP data as a result of the road surface reflectivity is not large, and cannot account for the difference between the two motorway $\mathrm{NO}_{2}$ values. Assuming an albedo of 0.2 instead of 0.05 , even in a clear Rayleigh atmosphere, the overestimation is below $23 \%$ for $\mathrm{NO}_{2}$ at the surface, where the albedo influence is largest (cf. Fig. 10). For elevated layers or in the presence of aerosols, this effect is even smaller.

The ability of AirMAP to map pollutants emitted from transport is especially advantageous when aiming to improve emission inventories and the predictive capability of regional modelling. Regular aircraft measurement campaigns focussing on motor traffic emissions that are complementary and coupled to the network of ground-based stations may provide invaluable insight into these variable pollutant emissions and distributions.

\section{Conclusions and outlook}

The AirMAP imaging DOAS instrument has been characterized and was successfully applied during an airborne operation in June 2011. In its current set-up, the instrument is adjusted for measurements of $\mathrm{NO}_{2}$ column amounts be- low the aircraft. The AirMAP instrument and associated data analysis differ from previous studies in several aspects. The present study demonstrates the mapping of comparably small-scale $\mathrm{NO}_{2}$ abundances at good spatial coverage and resolution. The wide and continuous spatial coverage is achieved by (a) a wide field of view of $48^{\circ}$ across track and (b) a measurement sequence without temporal gaps between consecutive exposures. Independent of flight altitude, the instrument provides smooth trace gas maps. The instrument is hence capable of covering large areas with trace gas observations within a comparably short time. Previously reported instruments with opening angles up to $30^{\circ}$ require nearly twice the length of time to cover the same area. As an example, AirMAP would achieve full coverage of a typical satellite pixel of GOME-2 $\left(40 \times 80 \mathrm{~km}^{2}\right)$ or OMI $\left(13 \times 24 \mathrm{~km}^{2}\right)$ at a flight altitude of around $3 \mathrm{~km}$, and an air speed around $80 \mathrm{~m} \mathrm{~s}^{-1}$, within $4.5 \mathrm{~h}$ or less than $1 \mathrm{~h}$, respectively, with pixel sizes below $100 \mathrm{~m}$ side length at full resolution of 35 viewing directions.

Flexible integration of the instrument into the aircraft is facilitated through an optical light guide with sorted fibres, allowing up to 35 individual viewing directions simultaneously. At full spatial resolution, a ground pixel size of $30 \times 30 \mathrm{~m}^{2}$ is enabled for present flight conditions. At such fine spatial resolution, accurate geolocation of the observations is required. In contrast to some previous studies on airborne $\mathrm{NO}_{2}$ measurements, the aircraft attitude is taken fully into account. In relation to the pixel sizes, computed displacements are significant for the investigated survey flight. Accurate geolocation has been achieved during typically unlevel flight conditions and even during strongly curved flight paths by use of AHRS positioning data. Good spatial imaging and the accurate assignment of the observations to ground locations have been demonstrated.

Trace gas retrievals with AirMAP benefit from good spectral stability and resolution. The $\mathrm{NO}_{2}$ vertical column detection limit is around $2 \times 10^{15}$ molec cm$~_{-2}$ for individual $0.5 \mathrm{~s}$ exposures from the LOS09 retrieval at an across-track resolution of around $100 \mathrm{~m}$. As an application example, $\mathrm{NO}_{2}$ emissions of a medium-sized power plant in north-west Germany were observed and investigated using both a coarser resolution and the full spatial resolution capacity of AirMAP. The measurements demonstrate strong spatial $\mathrm{NO}_{2}$ variability across and along track. This makes the high spatial resolution of AirMAP particularly useful. The emission plume is clearly detected downwind of the power plant stack, and $\mathrm{NO}_{2}$ results are consistent for the two cases of different spatial resolution. The internal plume structure is partly non-uniform and indicates non-uniform behaviour of the emissions, the chemical conversions and/or local meteorology and transport. Emission flux estimates are performed, and extrapolated results under the given assumptions are in reasonable agreement with annual emission reports from the power plant operators. The good spatial coverage and resolution of the AirMAP instrument allows specific and detailed observation 

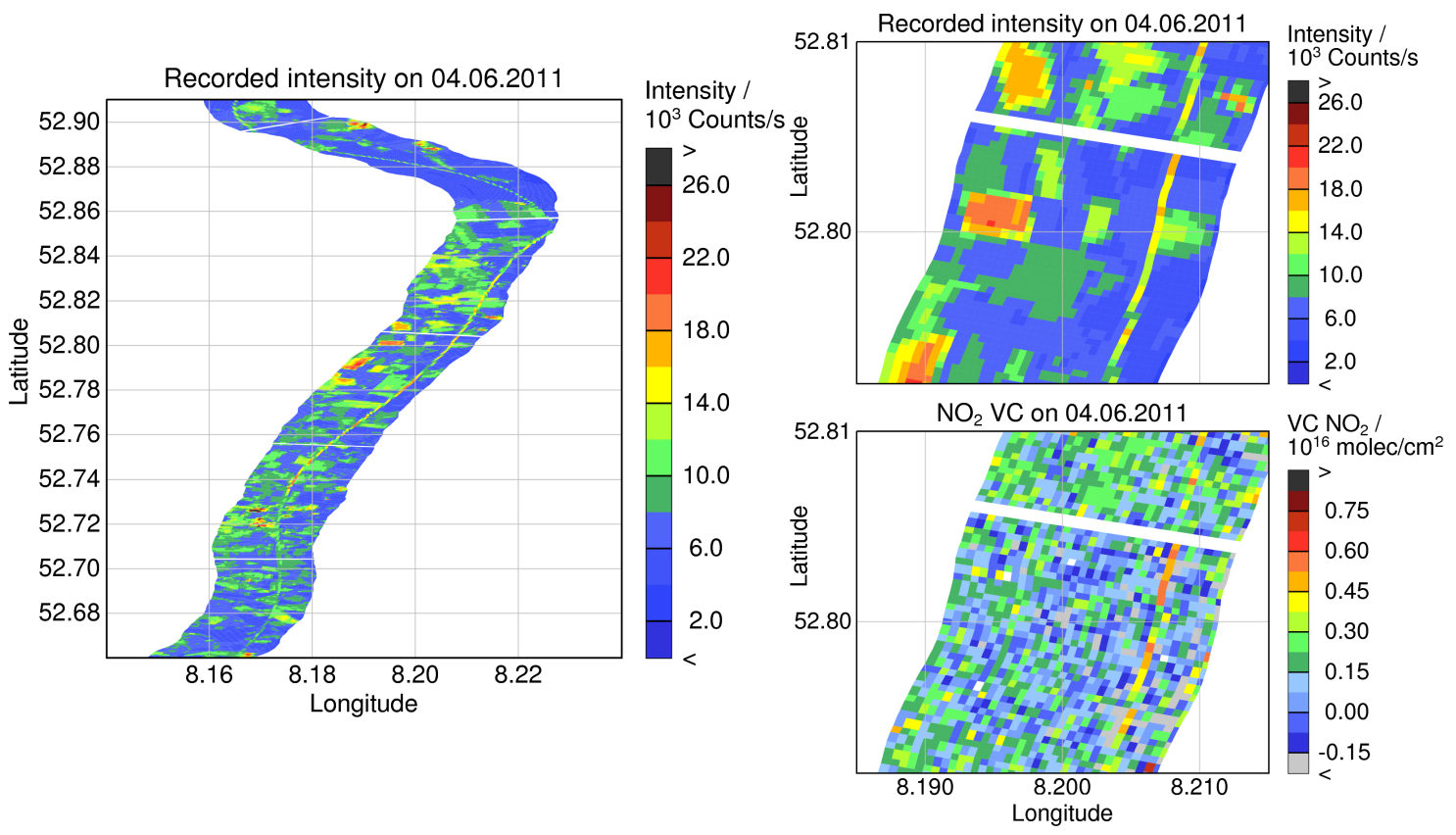

Figure 19. Flight section along the motorway A1 in north-west Germany. The recorded intensity (left) is enhanced above the motorway and in addition above bright fields. The two maps on the right show an excerpt of the flight section, the recorded intensity (top) and the $\mathrm{NO}_{2}$ $\mathrm{VC}$ (bottom). The reflected intensity is enhanced above the motorway and even more above a field on the western side of the swath. $\mathrm{NO}_{2}$ amounts above the motorway are also enhanced, but not above the bright field.

and analysis of exhaust plumes and their temporal evolution, also in future applications. At full spatial resolution, local enhancements of $\mathrm{NO}_{2}$ columns above a motorway have been detected and investigated for a short flight section as an illustration of the potential of the AirMAP small-scale observations. Such observations in a campaign or on a regular basis are invaluable for the improvement of emission inventories and as a reference for regional modelling. The current spectrometer configuration was focussed on $\mathrm{NO}_{2}$; minor modifications in the spectrometer set-up enable observations of other key trace gases such as formaldehyde, $\mathrm{HCHO}$, and glyoxal, $\mathrm{CHOCHO}$, as well as sulfur dioxide, $\mathrm{SO}_{2}$, water vapour, $\mathrm{H}_{2} \mathrm{O}$, and halogen oxides ( $\mathrm{BrO}, \mathrm{OClO}$ and $\left.\mathrm{IO}\right)$.

In conclusion, the present study demonstrates the successful operation of the AirMAP instrument, in particular the achievement of good spatial resolution and coverage, as well as the high instrument quality in terms of spatial imaging and accurate geolocation. Good spectral quality and stability support the successful observation of $\mathrm{NO}_{2}$ on small spatial scales. The good mapping capability of AirMap is to be used in the future for scientific investigations focussing on smallscale spatial variability of tropospheric trace species.

Acknowledgements. Financial support for the AirMAP project by the State and University of Bremen is gratefully acknowledged. The project is supported through the University of Bremen Institutional Strategy in the framework of the Excellence Initiative. The AIRMETH-2011 campaign was jointly funded by the Alfred We- gener Institute for Polar and Marine Sciences (AWI), the Helmholtz Centre Potsdam (German Research Centre for Geosciences, GFZ) and the University of Bremen.

The authors are grateful to AWI Bremerhaven and Fielax, especially to Martin Gehrmann and Franziska Nehring, for their dedicated and essential campaign support. Support by the AIRMETH team is acknowledged for including AirMAP in the campaign configuration. The Polar-5 aircraft was kindly operated by Kenn Borek Air Ltd, Canada. COSMO-DE model data were obtained from the German Weather Service (DWD). The authors are thankful to Thomas Krings for discussions on the wind data, and to Vladimir Rozanov for his support on the RT code SCIATRAN.

The article processing charges for this open-access publication were covered by the University of Bremen.

Edited by: J. Stutz

\section{References}

Baidar, S., Oetjen, H., Coburn, S., Dix, B., Ortega, I., Sinreich, R., and Volkamer, R.: The CU Airborne MAX-DOAS instrument: vertical profiling of aerosol extinction and trace gases, Atmos. Meas. Tech., 6, 719-739, doi:10.5194/amt-6-719-2013, 2013.

Beirle, S., Platt, U., Wenig, M., and Wagner, T.: Weekly cycle of $\mathrm{NO}_{2}$ by GOME measurements: a signature of anthropogenic sources, Atmos. Chem. Phys., 3, 2225-2232, doi:10.5194/acp3-2225-2003, 2003. 
Berg, N., Mellqvist, J., Jalkanen, J.-P., and Balzani, J.: Ship emissions of $\mathrm{SO}_{2}$ and $\mathrm{NO}_{2}$ : DOAS measurements from airborne platforms, Atmos. Meas. Tech., 5, 1085-1098, doi:10.5194/amt-51085-2012, 2012.

Bobrowski, N., Hönninger, G., Lohberger, F., and Platt, U.: IDOAS: A new monitoring technique to study the 2D distribution of volcanic gas emissions, J. Volcanol. Geotherm. Res., 150, 329-338, doi:10.1016/j.jvolgeores.2005.05.004, 2006.

Brewer, A. W., McElroy, C. T., and Kerr, J. B.: Nitrogen dioxide concentrations in the atmosphere, Nature, 246, 129-133, 1973.

Bruns, M.: $\mathrm{NO}_{2}$ Profile Retrieval using Airborne Multiaxis Differential Optical Absorption Spectrometer (AMAXDOAS) data, Ph.D. thesis, University Bremen, 2004.

Bruns, M., Buehler, S. A., Burrows, J. P., Heue, K.-P., Platt, U., Pundt, I., Richter, A., Rozanov, A., Wagner, T., and Wang, P.: Retrieval of Profile Information from Airborne Multi Axis UV/visible Skylight Absorption Measurements, Appl. Optics, 43, 4415-4426, 2004.

Bruns, M., Buehler, S. A., Burrows, J. P., Richter, A., Rozanov, A., Wang, P., Heue, K. P., Platt, U., Pundt, I., and Wagner, T.: $\mathrm{NO}_{2}$ Profile retrieval using airborne multi axis UV-visible skylight absorption measurements over central Europe, Atmos. Chem. Phys., 6, 3049-3058, doi:10.5194/acp-6-3049-2006, 2006.

Bucsela, E., Celarier, E., Wenig, M., Gleason, J., Veefkind, J., Boersma, K., and Brinksma, E.: Algorithm for $\mathrm{NO}_{2}$ vertical column retrieval from the ozone monitoring instrument, Geoscience and Remote Sensing, IEEE Transactions on, 44, 1245-1258, doi:10.1109/TGRS.2005.863715, 2006.

Burrows, J. P., Dehn, A., Deters, B., Himmelmann, S., Richter, A., Voigt, S., and Orphal, J.: Atmospheric remote sensing reference data from GOME: Part 1. temperature dependent absorption cross-sections of $\mathrm{NO}_{2}$ in the 231-794 nm Range, J. Quant. Spectrosc. Ra. Transfer, 60, 1025-1031, 1998.

Burrows, J. P., Richter, A., Dehn, A., Deters, B., Himmelmann, S., Voigt, S., and Orphal, J.: Atmospheric remote-sensing reference data from GOME: Part 2. Temperature-dependent absorption cross sections of $\mathrm{O}_{3}$ in the 231-794 nm range, J. Quant. Spectrosc. Ra. Transfer, 61, 509-517, doi:10.1016/S00224073(98)00037-5, 1999a.

Burrows, J. P., Weber, M., Buchwitz, M., Rozanov, V. V., LadstätterWeissenmayer, A., Richter, A., DeBeek, R., Hoogen, R., Bramstedt, K., and Eichmann, K. U.: The Global Ozone Monitoring Experiment (GOME): Mission Concept and First Scientific Results, J. Atmos. Sci., 56, 151-175, 1999b.

Davis, D. D., Smith, G., and Klauber, G.: Trace Gas Analysis of Power Plant Plumes Via Aircraft Measurement: $\mathrm{O}_{3}$, NO, and $\mathrm{SO}_{2}$ Chemistry, Science, 186, 733-736, 1974.

Dix, B., Brenninkmeijer, C. A. M., Frieß, U., Wagner, T., and Platt, U.: Airborne multi-axis DOAS measurements of atmospheric trace gases on CARIBIC long-distance flights, Atmos. Meas. Tech., 2, 639-652, doi:10.5194/amt-2-639-2009, 2009.

Doms, G. and Baldauf, M: A Description of the Nonhydrostatic Regional COSMO-Model, Deutscher Wetterdienst, Technical Report, May 2015, available at: http://www.cosmo-model.org/, last access: December 2015.

Ehhalt, D. H., Rohrer, F., and Wahner, A.: Sources and Distribution of $\mathrm{NO}_{\mathrm{x}}$ in the Upper Troposphere at Northern Mid-Latitudes, J. Geophys. Res., 97, 3723-3738, 1992.
Galloway, J., Likens, G., Keene, W., and Miller, J.: The Composition of precipitation in the remote areas of the world, J. Geophys. Res.-Oceans and Atmos., 87, 8771-8786, doi:10.1029/JC087iC11p08771, 1982.

General, S., Pöhler, D., Sihler, H., Bobrowski, N., Frieß, U., Zielcke, J., Horbanski, M., Shepson, P. B., Stirm, B. H., Simpson, W. R., Weber, K., Fischer, C., and Platt, U.: The Heidelberg Airborne Imaging DOAS Instrument (HAIDI) - a novel imaging DOAS device for 2-D and 3-D imaging of trace gases and aerosols, Atmos. Meas. Tech., 7, 3459-3485, doi:10.5194/amt7-3459-2014, 2014.

General, S., Bobrowski, N., Pöhler, D., Weber, K., Fischer, C., and Platt, U.: Airborne I-DOAS measurements at Mt. Etna: BrO and OClO evolution in the plume, J. Volcanol. Geotherm. Res., 300, 175-186, 2015.

Gerilowski, K., Tretner, A., Krings, T., Buchwitz, M., Bertagnolio, P. P., Belemezov, F., Erzinger, J., Burrows, J. P., and Bovensmann, H.: MAMAP - a new spectrometer system for columnaveraged methane and carbon dioxide observations from aircraft: instrument description and performance analysis, Atmos. Meas. Tech., 4, 215-243, doi:10.5194/amt-4-215-2011, 2011.

Greenblatt, G. D., Orlando, J. J., Burkholder, J. B., and Ravishankara, A. R.: Absorption Measurements of Oxygen Between 330 and 1140 nm, J. Geophys. Res., 95, 18577-18582, 1990.

Heue, K.-P., Richter, A., Bruns, M., Burrows, J. P., v. Friedeburg, C., Platt, U., Pundt, I., Wang, P., and Wagner, T.: Validation of SCIAMACHY tropospheric $\mathrm{NO}_{2}$-columns with AMAXDOAS measurements, Atmos. Chem. Phys., 5, 1039-1051, doi:10.5194/acp5-1039-2005, 2005.

Heue, K.-P., Wagner, T., Broccardo, S. P., Walter, D., Piketh, S. J., Ross, K. E., Beirle, S., and Platt, U.: Direct observation of two dimensional trace gas distributions with an airborne Imaging DOAS instrument, Atmos. Chem. Phys., 8, 6707-6717, doi:10.5194/acp-8-6707-2008, 2008.

Heue, K.-P., Brenninkmeijer, C. A. M., Baker, A. K., RautheSchöch, A., Walter, D., Wagner, T., Hörmann, C., Sihler, H., Dix, B., Frieß, U., Platt, U., Martinsson, B. G., van Velthoven, P. F. J., Zahn, A., and Ebinghaus, R.: $\mathrm{SO}_{2}$ and BrO observation in the plume of the Eyjafjallajökull volcano 2010: CARIBIC and GOME-2 retrievals, Atmos. Chem. Phys., 11, 2973-2989, doi:10.5194/acp-11-2973-2011, 2011.

Hilboll, A., Richter, A., and Burrows, J. P.: Long-term changes of tropospheric $\mathrm{NO}_{2}$ over megacities derived from multiple satellite instruments, Atmos. Chem. Phys., 13, 4145-4169, doi:10.5194/acp-13-4145-2013, 2013.

Hönninger, G., von Friedeburg, C., and Platt, U.: Multi axis differential optical absorption spectroscopy (MAX-DOAS), Atmos. Chem. Phys., 4, 231-254, doi:10.5194/acp-4-231-2004, 2004.

Ibrahim, O., Shaiganfar, R., Sinreich, R., Stein, T., Platt, U., and Wagner, T.: Car MAX-DOAS measurements around entire cities: quantification of $\mathrm{NO}_{x}$ emissions from the cities of Mannheim and Ludwigshafen (Germany), Atmos. Meas. Tech., 3, 709-721, doi:10.5194/amt-3-709-2010, 2010.

Itten, K. I., Dell'Endice, F., Hueni, A., Kneubühler, M., Schläpfer, D., Odermatt, D., Seidel, F., Huber, S., Schopfer, J., Kellenberger, T., Bühler, Y., D'Odorico, P., Nieke, J., Alberti, E., and Meuleman, K.: APEX - the Hyperspectral ESA Airborne Prism Experiment, Sensors, 8, 6235-6259, doi:10.3390/s8106235, 2008. 
Krings, T., Gerilowski, K., Buchwitz, M., Hartmann, J., Sachs, T., Erzinger, J., Burrows, J. P., and Bovensmann, H.: Quantification of methane emission rates from coal mine ventilation shafts using airborne remote sensing data, Atmos. Meas. Tech., 6, 151-166, doi:10.5194/amt-6-151-2013, 2013.

Leitão, J., Richter, A., Vrekoussis, M., Kokhanovsky, A., Zhang, Q. J., Beekmann, M., and Burrows, J. P.: On the improvement of $\mathrm{NO}_{2}$ satellite retrievals - aerosol impact on the airmass factors, Atmos. Meas. Tech., 3, 475-493, doi:10.5194/amt-3-475-2010, 2010.

Leue, C., Wenig, M., Wagner, T., Klimm, O., Platt, U., and Jähne, B.: Quantitative analysis of $\mathrm{NO}_{\mathrm{x}}$ emissions from Global Ozone Monitoring Experiment satellite image sequences, J. Geophys. Res.-Atmos., 106, 5493-5505, doi:10.1029/2000JD900572, 2001

Levelt, P., Hilsenrath, E., Leppelmeier, G., van den Oord, G., Bhartia, P., Tamminen, J., de Haan, J., and Veefkind, J.: Science Objectives of the Ozone Monitoring Instrument,, IEEE Trans. Geo. Rem. Sens., 44, 1199-1208, doi:10.1109/TGRS.2006.872336, 2006.

Lohberger, F., Hönninger, G., and Platt, U.: Ground-based imaging differential optical absorption spectroscopy of atmospheric gases, Appl. Optics, 43, 4711-4717, 2004.

Melamed, M. L., Solomon, S., Daniel, J. S., Langford, A. O., Portmann, R. W., Ryerson, T. B., Nicks, Jr., D. K., and McKeen, S. A.: Measuring reactive nitrogen emissions from point sources using visible spectroscopy from aircraft, J. Environ. Monit., 5, 29-34, doi:10.1039/B204220G, 2003.

Merlaud, A., Van Roozendael, M., van Gent, J., Fayt, C., Maes, J., Toledo-Fuentes, X., Ronveaux, O., and De Mazière, M.: DOAS measurements of $\mathrm{NO}_{2}$ from an ultralight aircraft during the Earth Challenge expedition, Atmos. Meas. Tech., 5, 2057-2068, doi:10.5194/amt-5-2057-2012, 2012.

Nitschke, M., Smith, B., Pilotto, L., Pisaniello, D., Abramson, M., and Ruffin, R.: Respiratory health effects of nitrogen dioxide exposure and current guidelines, Int. J. Environ. Health Res., 9, 3953, doi:10.1080/09603129973344, 1999.

Noxon, J. F.: Nitrogen Dioxide in the Stratosphere and Troposphere measured by ground-based absorption spectroscopy, Science, 189, 547, 1975.

Paerl, H.: Enhancement of marine primary production by nitrogen-enriched acid-rain, Nature, 315, 747-749, doi:10.1038/315747a0, 1985

Peters, E., Wittrock, F., Großmann, K., Frieß, U., Richter, A., and Burrows, J. P.: Formaldehyde and nitrogen dioxide over the remote western Pacific Ocean: SCIAMACHY and GOME-2 validation using ship-based MAX-DOAS observations, Atmos. Chem. Phys., 12, 11179-11197, doi:10.5194/acp-12-111792012, 2012.

Pfeilsticker, K. and Platt, U.: Airborne measurements during the Arctic Stratospheric Experiment: Observation of $\mathrm{O}_{3}$ and $\mathrm{NO}_{2}$, Geophys. Res. Lett., 21, 1375-1378, doi:10.1029/93GL01870, 1994.

Platt, U. and Perner, D.: Direct measurements of atmospheric $\mathrm{CH}_{2} \mathrm{O}, \mathrm{HNO}_{2}, \mathrm{O}_{3}, \mathrm{NO}_{2}, \mathrm{SO}_{2}$ by differential optical absorption in the near UV, J. Geophys. Res., 85, 7453-7458, 1980.

Platt, U. and Stutz, J.: Differential Optical Absorption Spectroscopy - Principles and Applications, Springer-Verlag, 2008.
Popp, C., Brunner, D., Damm, A., Van Roozendael, M., Fayt, C., and Buchmann, B.: High-resolution $\mathrm{NO}_{2}$ remote sensing from the Airborne Prism EXperiment (APEX) imaging spectrometer, Atmos. Meas. Tech., 5, 2211-2225, doi:10.5194/amt-5-22112012, 2012.

Pundt, I., Mettendorf, K., Laepple, T., Knab, V., Xie, P., Lösch, J., Friedeburg, C., Platt, U., and Wagner, T.: Measurements of trace gas distributions using Long-path DOASTomography during the motorway campaign BAB II: experimental setup and results for $\mathrm{NO}_{2}$, Atmos. Environ., 39, 967-975, doi:10.1016/j.atmosenv.2004.07.035, 2005.

Richter, A. and Burrows, J.: Tropospheric $\mathrm{NO}_{2}$ from GOME Measurements, Adv. Space Res., 29, 1673-1683, 2002.

Richter, A., Burrows, J. P., Nüß, H., Granier, C., and Niemeier, U.: Increase in tropospheric nitrogen dioxide over China observed from space, Nature, 437, 129-132, doi:10.1038/nature04092, 2005.

Rothman, L., Jacquemart, D., Barbe, A., Benner, D. C., Birk, M., Brown, L., Carleer, M., Jr., C. C., Chance, K., Coudert, L., Dana, V., Devi, V., Flaud, J.-M., Gamache, R., Goldman, A., Hartmann, J.-M., Jucks, K., Maki, A., Mandin, J.Y., Massie, S., Orphal, J., Perrin, A., Rinsland, C., Smith, M., Tennyson, J., Tolchenov, R., Toth, R., Auwera, J. V., Varanasi, P., and Wagner, G.: The HITRAN 2004 molecular spectroscopic database, J. Quant. Spectrosc. Ra. Transfer, 96, 139-204, doi:10.1016/j.jqsrt.2004.10.008, 2005.

Rozanov, V., Buchwitz, M., Eichmann, K.-U., de Beek, R., and Burrows, J.: Sciatran - A new radiative transfer model for geophysical applications in the 240-2400 nm spectral region: The Pseudospherical version, Adv. Space Res., 29, 1831-1835, 2002.

Schowengerdt, R. A.: Remote Sensing - Models and Methods for Image Processing (Third Edition), Academic Press, Burlington, 2007.

Vountas, M., Richter, A., Wittrock, F., and Burrows, J. P.: Inelastic scattering in ocean water and its impact on trace gas retrievals from satellite data, Atmos. Chem. Phys., 3, 1365-1375, doi:10.5194/acp-3-1365-2003, 2003.

Wang, P., Richter, A., Bruns, M., Rozanov, V. V., Burrows, J. P., Heue, K.-P., Wagner, T., Pundt, I., and Platt, U.: Measurements of tropospheric $\mathrm{NO}_{2}$ with an airborne multi-axis DOAS instrument, Atmos. Chem. Phys., 5, 337-343, doi:10.5194/acp-5-337-2005, 2005.

Wang, P., Richter, A., Bruns, M., Burrows, J. P., Scheele, R., Junkermann, W., Heue, K.-P., Wagner, T., Platt, U., and Pundt, I.: Airborne multi-axis DOAS measurements of tropospheric $\mathrm{SO}_{2}$ plumes in the Po-valley, Italy, Atmos. Chem. Phys., 6, 329-338, doi:10.5194/acp-6-329-2006, 2006.

Wittrock, F., Oetjen, H., Richter, A., Fietkau, S., Medeke, T., Rozanov, A., and Burrows, J. P.: MAX-DOAS measurements of atmospheric trace gases in Ny-Ålesund - Radiative transfer studies and their application, Atmos. Chem. Phys., 4, 955-966, doi:10.5194/acp-4-955-2004, 2004. 